\title{
Electrochemical and Optical Properties of Magnesium-Alloy Hydrides Reviewed
}

\author{
Thirugnasambandam G. Manivasagam ${ }^{1, *}$, Kamil Kiraz $^{1}$ and Peter H. L. Notten ${ }^{1,2}$ \\ 1 Department of Chemical Engineering and Chemistry, Eindhoven University of Technology, \\ MB Eindhoven 5600, The Netherlands; E-Mails: k.kiraz@tue.nl (K.K.); \\ p.h.1.notten@tue.nl (P.H.L.N.) \\ 2 Department of Electrical Engineering, Eindhoven University of Technology, MB Eindhoven 5600, \\ The Netherlands
}

* Author to whom correspondence should be addressed; E-Mail: t.g.manivasagam@tue.nl; Tel.: +31-40-247-2369; Fax: +31-40-247-3481.

Received: 18 April 2012; in revised form: 30 July 2012 / Accepted: 10 August 2012 /

Published: 15 October 2012

\begin{abstract}
As potential hydrogen storage media, magnesium based hydrides have been systematically studied in order to improve reversibility, storage capacity, kinetics and thermodynamics. The present article deals with the electrochemical and optical properties of $\mathrm{Mg}$ alloy hydrides. Electrochemical hydrogenation, compared to conventional gas phase hydrogen loading, provides precise control with only moderate reaction conditions. Interestingly, the alloy composition determines the crystallographic nature of the metalhydride: a structural change is induced from rutile to fluorite at 80 at. $\%$ of $\mathrm{Mg}$ in $\mathrm{Mg}-\mathrm{TM}$ alloy, with ensuing improved hydrogen mobility and storage capacity. So far, 6 wt.\% (equivalent to $1600 \mathrm{mAh} / \mathrm{g}$ ) of reversibly stored hydrogen in $\mathrm{Mg}_{\mathrm{y}} \mathrm{TM}_{(1-\mathrm{y})} \mathrm{H}_{\mathrm{x}}(\mathrm{TM}$ : Sc, Ti) has been reported. Thin film forms of these metal-hydrides reveal interesting electrochromic properties as a function of hydrogen content. Optical switching occurs during (de)hydrogenation between the reflective metal and the transparent metal hydride states. The chronological sequence of the optical improvements in optically active metal hydrides starts with the rare earth systems $\left(\mathrm{YH}_{\mathrm{x}}\right)$, followed by $\mathrm{Mg}$ rare earth alloy hydrides $\left(\mathrm{Mg}_{\mathrm{y}} \mathrm{Gd}_{(1-\mathrm{y})} \mathrm{H}_{\mathrm{x}}\right)$ and concludes with $\mathrm{Mg}$ transition metal hydrides $\left(\mathrm{Mg}_{\mathrm{y}} \mathrm{TM}_{(1-\mathrm{y})} \mathrm{H}_{\mathrm{x}}\right)$. In-situ optical characterization of gradient thin films during (de)hydrogenation, denoted as hydrogenography, enables the monitoring of alloy composition gradients simultaneously.
\end{abstract}


Keywords: hydrogen storage; magnesium hydride; switchable mirrors; bulk powders; thin films; electrochemical hydrogenation; gas phase hydrogenation

\section{Introduction}

The depleting fossil fuel resources and altering climate conditions increases the necessity for alternative sustainable energy technologies. Among the green-house gases, $\mathrm{CO}_{2}$ emission from burning fossil fuels has been especially identified as the main perpetrator for the undesirable climate change. The $\mathrm{CO}_{2}$ emission has increased from 20.7 billion tonnes (Gt) in 1990 to $32.5 \mathrm{Gt}$ in 2006 (9.9 Gt of carbon equivalent) [1]. Furthermore, the oil and natural gas reserves are expected to decrease within a few decades. Among the available alternative energy sources such as solar, wind, tidal, geothermal, etc., the hydrogen economy seems advantageous, considering its wide-spread availability, high storage capacity, utilization, efficiency, and environmental compatibility [2]. Hydrogen is therefore expected to play a dominant role in future energy scenarios as a promising energy carrier. It undergoes a clean combustion reaction with oxygen, producing energy and water only, according to

$$
\mathrm{H}_{2(\mathrm{~g})}+\frac{1}{2} \mathrm{O}_{2(\mathrm{~g})} \rightarrow \mathrm{H}_{2} \mathrm{O}_{(\mathrm{l})}\left(\Delta H_{f}^{\circ}=-285.8 \mathrm{~kJ} / \mathrm{mol} \text { at } 25^{\circ} \mathrm{C}\right)
$$

On the other hand, for example, in the combustion reaction of the natural gas methane, $\mathrm{CO}_{2}$ is the dominant byproduct, which obviously is an undesirable green-house gas.

$$
\mathrm{CH}_{4(\mathrm{~g})}+2 \mathrm{O}_{2(\mathrm{~g})} \rightarrow \mathrm{CO}_{2(\mathrm{~g})}+2 \mathrm{H}_{2} \mathrm{O}_{(\mathrm{g})}\left(\Delta H_{f}^{\circ}=-802.3 \mathrm{~kJ} / \mathrm{mol} \text { at } 25^{\circ} \mathrm{C}\right)
$$

The energy per mass of hydrogen $\left(142 \mathrm{MJ} \mathrm{kg}^{-1}\right)$ is favorably much higher than that of other chemical fuels, such as liquid hydrocarbons $\left(47 \mathrm{MJ} \mathrm{kg}^{-1}\right)$ [3,4]. Conventionally, $\mathrm{H}_{2}$ is generally stored in high-pressure cylinders to increase the volumetric density [5]. Novel high-pressure tanks made of composites are currently being developed which can withstand more than 700 bars [4]. Even though these cylinders can withstand high pressures, their large volume and the risk of explosion limit their practical applications. On the other hand, condensation under cryogenic conditions seems to be attractive due to a significant increase in the volumetric density of up to $70.8 \mathrm{~kg} / \mathrm{m}^{3}$. However, liquid hydrogen containers are open systems and the loss of hydrogen is therefore hard to control. Alternatively, significant density increases can also be achieved by storing hydrogen in the form of metal-hydrides. It is interesting to realize that the density of hydrogen in metal-hydrides is often even higher than in liquid hydrogen. Due to the limited amount of free $\mathrm{H}_{2}$ gas that is in equilibrium with that stored in the solid, the metal-hydrides offer a relatively safe storage. Table 1 lists the comparison of hydrogen content and energy density information of several storage media.

The reversible hydrogen absorption and desorption capability of numerous metals and intermetallic compounds have already been known for a long period of time [6]. The discovery in the late 1960s at the Dutch Philips Research laboratories showed that the intermetallic compound $\mathrm{LaNi}_{5}$ is able to absorb a significant amount of hydrogen gas reversibly. Soon after this discovery it was realized that electrodes made of $\mathrm{LaNi}_{5}$ could serve as new electrochemical storage medium and could become a competitive alternative for the cadmium electrode in conventional Ni-Cd batteries. Even though $\mathrm{LaNi}_{5}$ can reversibly absorb and desorb a large amount of hydrogen under ambient conditions, the 
gravimetric capacity is still relatively low, about $1.2 \mathrm{wt} . \%$ of Hydrogen [7]. Considering the cost, availability and gravimetric storage capacity, magnesium is therefore, in principle, a much more suitable candidate with a storage capacity of up to $7.6 \mathrm{wt} . \%$ of hydrogen (see Table 1).

Table 1. Hydrogen content and energy density in various media [8].

\begin{tabular}{|c|c|c|c|c|}
\hline \multirow[t]{2}{*}{ Medium } & \multirow{2}{*}{$\begin{array}{c}\text { Hydrogen } \\
\text { Content } \\
\text { (wt. \%) }\end{array}$} & \multirow{2}{*}{$\begin{array}{c}\text { Volume Density } \\
\left(\mathrm{H}_{\text {atoms }} \mathrm{I}^{-1}\right) \\
\left(\mathbf{1 0}^{-19}\right)\end{array}$} & \multicolumn{2}{|c|}{ Energy Density $^{* *}$} \\
\hline & & & MJ $\mathbf{k g}^{-1}$ & $\mathbf{m J} \mathbf{I}^{-1}$ \\
\hline$H_{2(g)}(150$ atm $)$ & 100.00 & 0.5 & 141.90 & 1.02 \\
\hline $\mathrm{H}_{2}$ (I) $\left(-253^{\circ} \mathrm{C}\right)$ & 100.00 & 4.2 & 141.90 & 9.92 \\
\hline $\mathrm{MgH}_{2}$ & 7.65 & 6.7 & 9.92 & 14.32 \\
\hline $\mathrm{VH}_{2}$ & 2.10 & 11.4 & - & - \\
\hline $\mathrm{Mg}_{2} \mathrm{NiH}_{4}$ & 3.60 & 5.9 & 4.48 & 11.49 \\
\hline TiFeH$_{1.95}$ & 1.95 & 5.5 & 2.47 & 13.56 \\
\hline $\operatorname{LaNi}_{5} \mathbf{H}_{6.7}$ & 1.50 & 7.6 & 1.94 & 12.77 \\
\hline $\mathrm{ZrMn}_{2} \mathrm{H}_{3.6}$ & 1.75 & 6.0 & - & - \\
\hline $\mathrm{ZrMn}_{2} \mathrm{Fe}_{0.8} \mathrm{H}_{3.4}$ & 1.38 & 4.8 & - & - \\
\hline
\end{tabular}

In comparison to the other metal-hydrides, $\mathrm{MgH}_{2}$ has a relatively high energy density of $9.92 \mathrm{MJ} / \mathrm{kg}$ [8]. Although $\mathrm{Mg}$ fulfills major requirements for serving as a novel hydrogen storage material, it cannot be used in practical applications due to its poor (de)sorption kinetics and high (de)hydrogenation reaction temperature $\left(350-400{ }^{\circ} \mathrm{C}\right)$. The poor kinetics for the hydrogenation has been ascribed to two consecutive facts: the dissociation of the hydrogen molecules is hindered by the oxidation of the Mg surface and the hydrogen diffusion is limited in the rutile structure [9]. Despite these drawbacks, the lightweight property, high energy density and low cost make Mg-hydride a potentially promising hydrogen storage material for mobile applications.

Mg-based systems can be modified to improve the sorption properties, such as temperature (thermodynamics) and reaction rate (kinetics). It has been recognised that magnesium can be modified in different ways, i.e., forming nano particles, alloying $\mathrm{Mg}$ with transition metals and adding catalysts. This review will focus on the electrochemical and optical properties of the bulk and thin film Mg-TM alloy hydrides.

\section{Gas Phase versus Electrochemical Hydrogen Storage}

Many metals and alloys are capable of reversibly absorbing and desorbing large amounts of hydrogen. Loading can be done either by introducing molecular hydrogen gas or reducing water in an electrolyte, as schematically indicated in Figure $1 \mathrm{a}$ and $\mathrm{b}$, respectively. Molecular hydrogen is dissociated at the surface and is subsequently absorbed inside the host lattice while two $\mathrm{H}$ atoms recombine to $\mathrm{H}_{2}$ molecules during the desorption process (Figure 1a).

$$
\begin{gathered}
2 M+\mathrm{H}_{2} \leftrightarrow 2 M \mathrm{H}_{a d} \\
M \mathrm{H}_{a d} \leftrightarrow M \mathrm{H}_{a b s}
\end{gathered}
$$


Figure 1. Schematic model for hydrogenation via (a) gas phase (b) electrolyte.

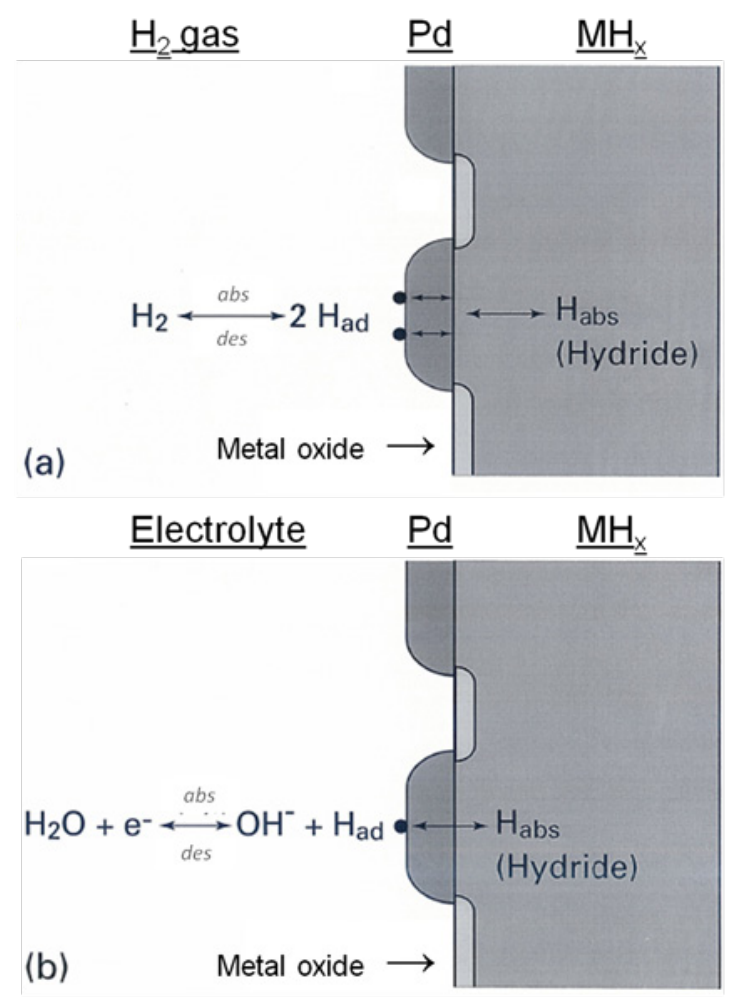

The thermodynamics of hydride formation via the gas phase can be elegantly described by Pressure-Composition-Isotherms (PCI) as shown in Figure 2. Initially a small amount of hydrogen $(\mathrm{H} / \mathrm{M}<0.1)$ is dissolved in the metal lattice during the absorption process and forms a solid solution, which is generally denoted as $\alpha$-phase. In this hydrogen concentration range the pressure increases as a function of hydrogen content. As the hydrogen concentration increases beyond a certain critical value $(\mathrm{H} / \mathrm{M}>0.1)$, the local interaction between hydrogen atoms dominates which leads to the nucleation and growth of a new hydride phase called $\beta$-phase, When the two phases coexists the isotherm exhibits a horizontal plateau region and, according to the phase rule, pressure independent characteristics are indeed expected in the plateau region. The length of the plateau is a function of hydrogen content. When all the $\alpha$-phase has been converted into the $\beta$-phase the pressure dependence is again rather strong and the hydrogen pressure raises steeply with hydrogen concentration. The plateau level is experimentally found to be a clear function of the temperature. Beyond the critical temperature $\left(\mathrm{T}_{\mathrm{c}}\right)$, no clear phase transition occurs anymore and only a solid solution is then present.

The equilibrium pressure depends on the temperature and is related to the change in both enthalpy $(\Delta \mathrm{H})$ and entropy $(\Delta \mathrm{S})$. The entropy change is mainly associated with the dissociation of hydrogen molecules into adsorbed $\mathrm{H}$-atoms at the surface of the hydride-forming material. As the entropy of the gas is the most dominant parameter, the entropy change is more or less the same for all known hydride systems and is dictated by the hydrogen in the gas phase. The enthalpy term is associated with the bond strength of hydrogen with the host material. The entropy and enthalpy values can be experimentally obtained from the Van 't Hoff relationship, according to

$$
\ln \left(\frac{p_{e q}}{p_{o}}\right)=\frac{\Delta H}{\mathrm{R} T}-\Delta S_{0} / \mathrm{R}
$$


where $\boldsymbol{p}_{\boldsymbol{e q}}$ and $\boldsymbol{p}_{\boldsymbol{o}}$ are equilibrium and standard pressures, respectively, $\Delta \boldsymbol{H}$ is the standard enthalpy change, $\boldsymbol{R}$ the gas constant, $\boldsymbol{T}$ the temperature and $\Delta \boldsymbol{S}_{\mathbf{0}}$ is the entropy change. The operating temperatures of the metal hydrides are determined by the equilibrium pressure and the overall reaction kinetics.

Figure 2. Pressure composition isotherms for hydrogen absorption [10].

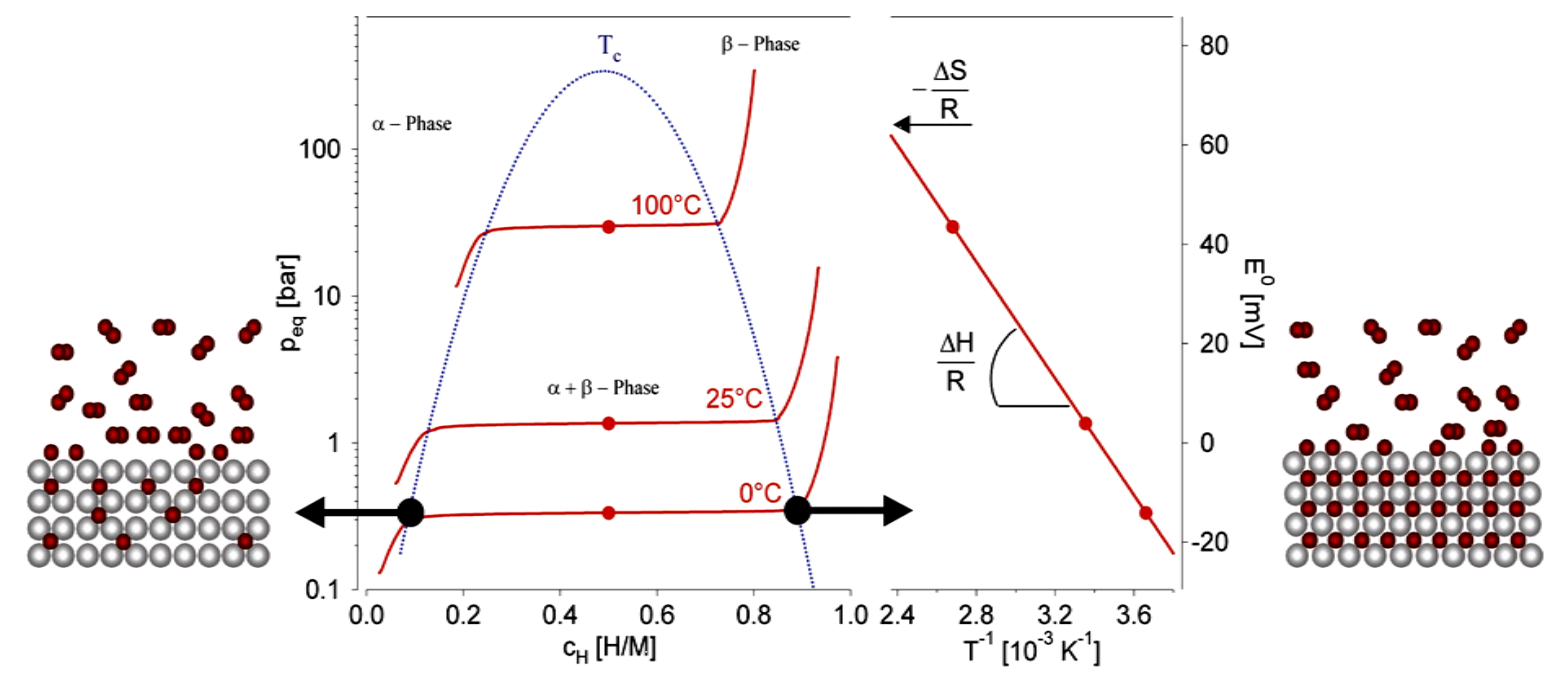

Another way to hydrogenate the host metal is by electrochemical reduction of water at a metallic electrode immersed in an alkaline solution, according to

$$
M+\mathrm{H}_{2} \mathrm{O}+e^{-} \leftrightarrow M_{\mathrm{ad}}+\mathrm{OH}^{-}
$$

This reversible process is also schematically indicated in Figure 1b. Subsequently, the adsorbed hydrogen atoms $\left(\mathrm{H}_{\mathrm{ad}}\right)$ are absorbed by the metal, leading to $\mathrm{H}_{\mathrm{abs}}$. In both cases, Pd addition prevents surface oxidation.

$$
M \mathrm{H}_{a d} \leftrightarrow M \mathrm{H}_{a b s}
$$

By changing the direction of the current, Equations (6) and (7) can be reversed and the absorbed hydrogen can reversibly be extracted from the host electrode. An advantage of this electrochemical method is that the hydrogen content can be precisely calculated from the amount of charge (Q) that is used during electrochemical (de)hydrogenation. Q can be quantified by integrating the current (I) with respect to time $(\mathrm{t})$ according to equation (8)

$$
Q=\int_{0}^{t \text { end }}|I| d t
$$

As every electron corresponds to a single $\mathrm{H}$ atom that is inserted or extracted, the number of absorbed/desorbed hydrogen atoms can easily be calculated from Q by using the faraday constant (F)

$$
\frac{Q}{F}=\text { mole } \mathrm{H}
$$

The exact hydrogen storage capacity per mass unit can then be calculated with respect to the total mass of the electrode material. 
To determine the thermodynamics, the electrochemical absorption and desorption properties in the equilibrium state of the metal-hydride system, the so-called Galvanostatic Intermittent Titration Technique (GITT) is often used. This method is based on collecting equilibrium potential data during partial (dis)charging-resting cycles in which short current pulses are followed by current-off voltage relaxation periods. It has been deduced that the equilibrium potential $\left(\mathrm{E}_{\mathrm{eq}}\right)$ of the fully relaxed metal-hydride electrode can be related to the partial hydrogen pressure $\left(P_{\mathrm{H}_{2}}\right)$.

$$
E_{e q}=\frac{R T}{n F} \ln \left(\frac{P_{H 2}}{P_{\text {ref }}}\right) v s . R H E
$$

where $\mathrm{P}_{\text {ref }}$ is the reference pressure $(1 \mathrm{bar})$ and RHE refers to the reversible hydrogen electrode as reference voltage [11].

\section{Applications of Metal-Hydrides}

\subsection{NiMH Battery}

Electrochemical hydrogen storage in metal hydrides $(\mathrm{MH})$ is primarily applied in aqueous NiMH secondary batteries. The alternative $\mathrm{MH}$ electrode is aimed to replace the Cd-electrode which is widely used in Ni-Cd batteries and is highly toxic. Moreover, $\mathrm{MH}$ electrodes reveal significantly improved storage capacities and (dis)charge kinetics.

A schematic representation of a complete NiMH battery, containing a hydride-forming electrode and a nickel electrode, is shown in Figure 3. Both the electrically insulating separator and porous electrodes are impregnated with a strong alkaline solution (concentrated $\mathrm{KOH}$ ) that provides the ionic conductivity between the two electrodes. The basic electrochemical reactions, occurring at both electrodes during charging and discharging can be represented by equations (11) and (12) respectively.

Figure 3. The concept of a sealed rechargeable Ni-metal hydride $(\mathrm{MH})$ battery seen from a schematic point of view [12].

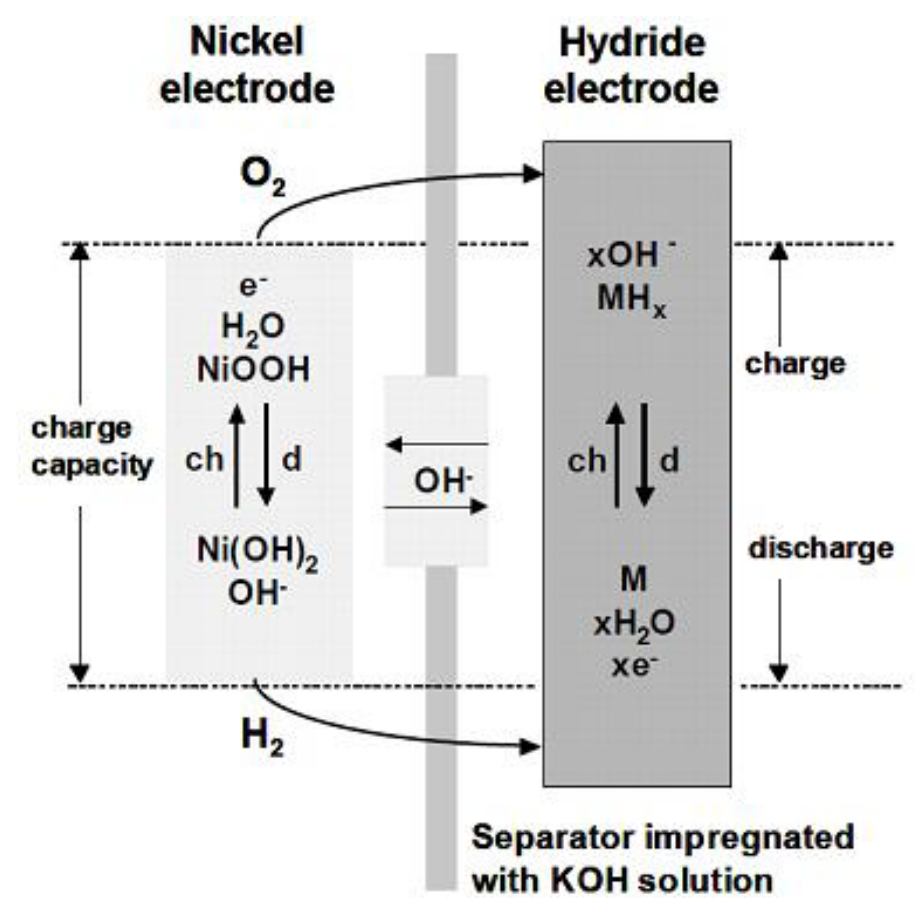




$$
\begin{gathered}
\mathrm{Ni}(\mathrm{OH})_{2}+\mathrm{OH}^{-} \underset{\text { discharging }}{\stackrel{\text { charging }}{\longrightarrow}} \mathrm{NiOOH}+\mathrm{H}_{2} \mathrm{O}+\mathrm{e}^{-} \\
M+\mathrm{H}_{2} \mathrm{O}+\mathrm{e}^{-} \underset{\text { discharging }}{\stackrel{\text { charging }}{\longrightarrow}} M \mathrm{H}+\mathrm{OH}^{-}
\end{gathered}
$$

During charging, divalent $\mathrm{Ni}(\mathrm{II})$ is oxidized to the trivalent $\mathrm{Ni}(\mathrm{III})$ state and water is reduced to hydrogen atoms which are first adsorbed on the metal electrode, which are then subsequently absorbed by the hydride-forming compound. The reverse reactions take place during discharging. The net effect of this reaction sequence (Equations 11 and 12) is that electrical charge is chemically stored in the electrode in the form of hydrogen. The reaction takes place without any water consumption preventing drying out of the battery unlike Ni-Cd batteries. The hydrogen storage alloy currently used in NiMH batteries is a Mischmetal-based $\mathrm{LaNi}_{5}$ compound. Researchers are still aiming to improve the properties of these materials mainly by focusing on the (dis)charge kinetics, storage capacity and corrosion resistance during over(dis)charging. Currently, the target sector of the NiMH battery technology is mainly mobile applications specifically Hybrid Electrical Vehicles (HEV) in the automotive industry [12].

\subsection{Electrochromic Applications}

Conceptually, 'electrochromism' is the reversible optical change of specific compounds in response to a change in the oxidation state of the involved electro-active species. The terminology was initially introduced by Platt in 1961 [13] for the color change of organic dyes under the influence of a strong electric field. The first extensive study was done by Deb in 1969 [14] in the field of inorganic metal oxide systems $\left(\mathrm{WO}_{3}\right)$. Numerous researchers both in industry and academically focused on different classes of electrochromic materials. The introduction of optically active metal-hydride thin films was reported by Huiberts et al. in 1996 and was based on yttrium- and lanthanum hydrides [15]. Metalhydrides expanded the classes of electrochromic materials and were listed among advanced optically switching inorganic compounds. Unlike most of the electrochromic color changing materials, metal hydrides even showed all three optical states (reflecting, absorbing and transmitting states) during the reversible (de)hydrogenation processes without any color change [16]. In this section, the development of optically active, hydride-forming materials are highlighted.

In the extensive work of Griessen et al., metal-hydride switchable mirrors can be classified into three generations: rare earth (RE) metal hydrides, magnesium - rare earth (MgRE) metal hydrides and magnesium-transition metal (MgTM) hydrides [16]. The leading work of Huiberts et al. focuses on the hydrogenation of rare earth yttrium thin films via the gas phase and in situ optical characterization of the transmission of the sample. The pressure-composition isotherm of a $300 \mathrm{~nm}$ Y film capped with a top layer of $15 \mathrm{~nm} \mathrm{Pd}$, indicated by black squares, is shown in Figure 4 together with the intensity of transmitted light (red circles). The optical transmission has been measured at $\lambda=635 \mathrm{~nm}(\hbar \omega=1,96$ $\mathrm{eV}$ ). Both the as-prepared metallic yttrium sample ( $\alpha$ phase) and the di-hydrided $\mathrm{YH}_{2}$ state ( $\beta$ phase) show almost no transmission whereas the tri-hydrided state at $\mathrm{x}=3$ ( $\gamma$ phase) has become optically transparent. Optical switching becomes saturated at composition $\mathrm{YH}_{2,86}[16]$. 
Figure 4. Pressure-Composition isotherm of yttrium film during gas phase hydrogenation (black square) and transmission spectrum depending on the hydrogen concentration (red circle) [16].

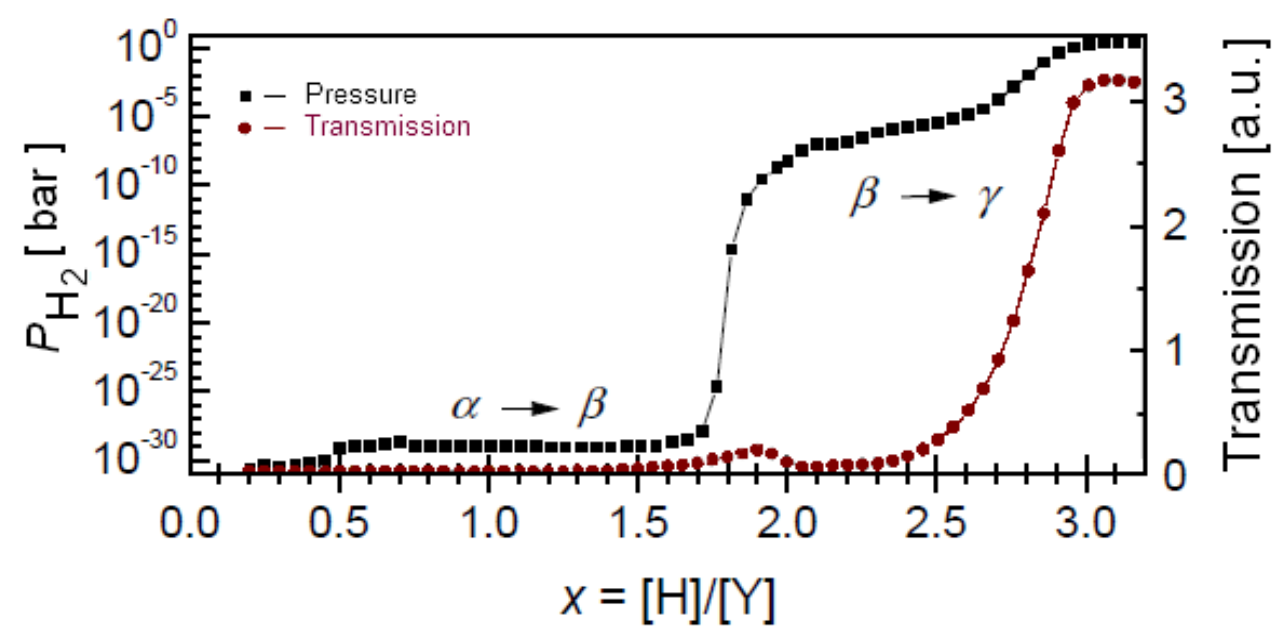

The first electrochemical hydrogenation experiments with combined optical analyses of yttrium film proved that optical switching can also be induced electrochemically in alkaline protective media, as is shown in Figure 6 [17]. Here a constant (de)hydrogenation current (1 mA) is applied to a $500 \mathrm{~nm}$ thick $\mathrm{Y}$ electrode that is capped with a $5 \mathrm{~nm}$ thick Pd-catalyst layer. Electrochemical (de)hydrogenation is performed in $6 \mathrm{M} \mathrm{KOH}$ electrolyte with $\mathrm{Pt}$ counter electrode and $\mathrm{Hg} / \mathrm{HgO}$ reference electrode. Optical switching is reported to take place in the hydrogen concentration range of $2.7<\mathrm{x}<2.8$ for $\mathrm{YH}_{\mathrm{x}}$. Electrochemical switching could be accomplished in the order of seconds during charging and minutes during discharging, revealing the slower dehydrogenation kinetics.

Figure 5. Electrode potential (solid black line) and optical transmission (dashed red line) intensity of yttrium film during electrochemical hydrogenation (a) and dehydrogenation (b) [17].

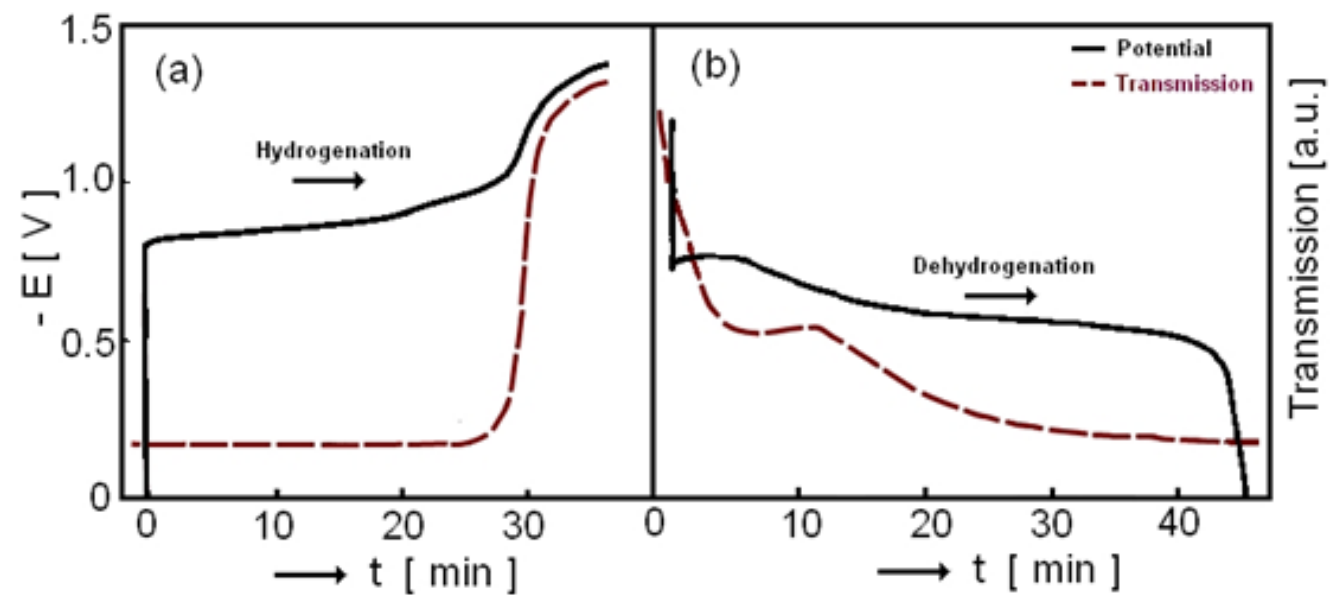

The second generation Mg-RE switchable mirrors, Gd-Mg alloys with different Gd to $\mathrm{Mg}$ ratios were optically examined during gas phase hydrogenation [18]. The effect of alloy composition for 
$\operatorname{Gd}_{1-\mathrm{x}} \mathrm{Mg}_{\mathrm{x}}$ binary alloys $(0 \leq \mathrm{x} \leq 0.9)$ on the transmission is reported in Figure 6 for a wide wavelength spectrum in the range of 200 to $1000 \mathrm{~nm}$.

Figure 6. Influence of Gd-Mg composition upon the transmission of $\mathrm{GdMgH}_{3}$ thin films [18].

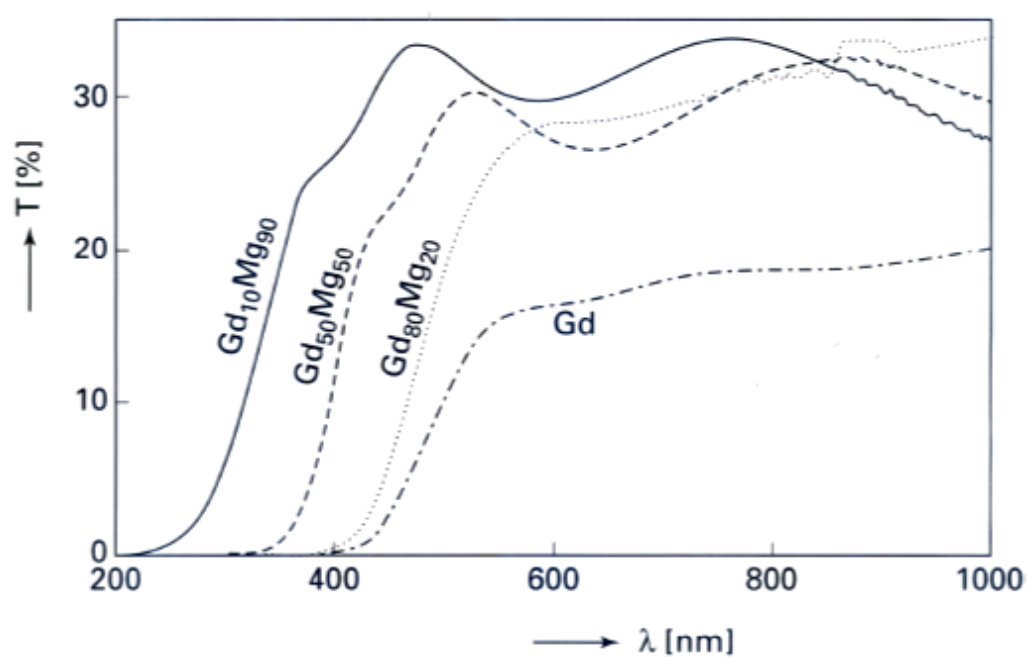

All samples in Figure 6 were $200 \mathrm{~nm}$ films, capped with $10 \mathrm{~nm}$ Pd and hydrogenated under a constant pressure of 5 bar of hydrogen at room temperature. In this work, magnesium was intended to be used as alloying element for the rare earth element Gd. Moreover, the color neutrality and transparency for gadolinium-magnesium hydride were remarkable and of significant importance for optical applications. In Figure 7, all three possible optical states can be seen during the transition from metallic $\mathrm{GdMg}$ to semiconducting $\mathrm{GdMgH}_{3}$.

Figure 7. Three optical states of $\mathrm{Mg}-\mathrm{Gd}$ switchable mirror: reflecting (a), absorbing (b) and transmitting (c) states [19].
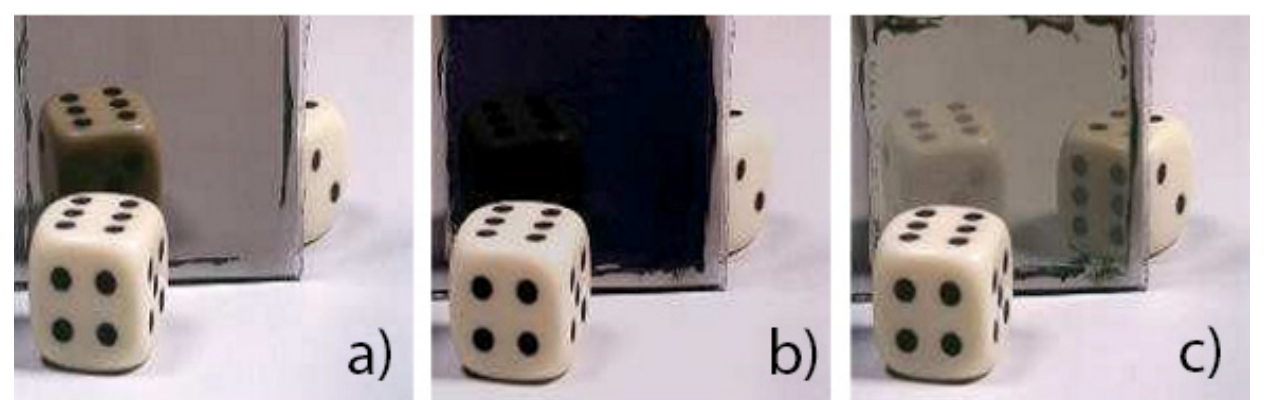

At the beginning of the new century, magnesium became the material of renewed interest not only from an optical point of view but also from an energy storage aspect. Various transition metals were investigated in order to control the kinetics of the (de)hydrogenation reaction. Niessen et al. showed that meta-stable alloys can be prepared in thin film form by depositing $\mathrm{Mg}$ with $\mathrm{Ti}, \mathrm{V}$ or $\mathrm{Cr}$, though they are immiscible elements from a thermodynamic point of view, [20]. The hydrogen content of these materials also strongly affects the optical properties, which can be used in hydrogen sensors, smart solar collectors and switchable mirrors. The pioneering work of the third generation of switchable mirrors, Mg-transition metals, is highlighted in Ref. [17] where the reversible optical transition of Mg-rich $\mathrm{Nb}$ binary alloys was carried out by Richardson et al. in 2001 [21]. 
Figure 8 shows the electrochemical (de)hydrogenation of a $50 \mathrm{~nm}$ thick $\mathrm{Mg}-\mathrm{Ni}$ film covered with a $10 \mathrm{~nm} \mathrm{Pd}$ top layer in $8 \mathrm{M} \mathrm{KOH}$. Nickel is an interesting alloying element, which is thermodynamically expected to destabilize $\mathrm{Mg}$. Optical switching of this material has also been confirmed in the gas phase under a stream of $4 \%$ hydrogen in argon or helium. Visual coloration has been reported as pale yellow in the Mg-rich region and deep red in the Ni-rich region in the hydride, transparent, state.

Figure 8. Electrochemical (de)hydrogenation cycle (line) with switching optical response (dashed) between reflective and transparent states of $\mathrm{Mg}-\mathrm{Ni}$ alloy and its hydride respectively [21].

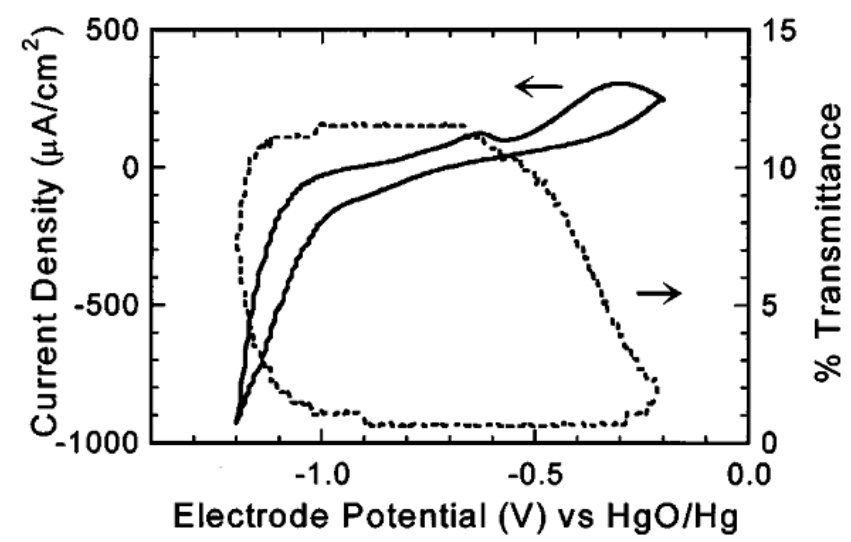

In order to understand the main concepts behind the different colorations, the optical states and visual responses during the metal-to-metal hydride transition, the energy band gap between the valence band and conduction band of the individual metal-hydride must be considered.

Figure 9. Fundamental band gaps of complex magnesium hydrides [22].

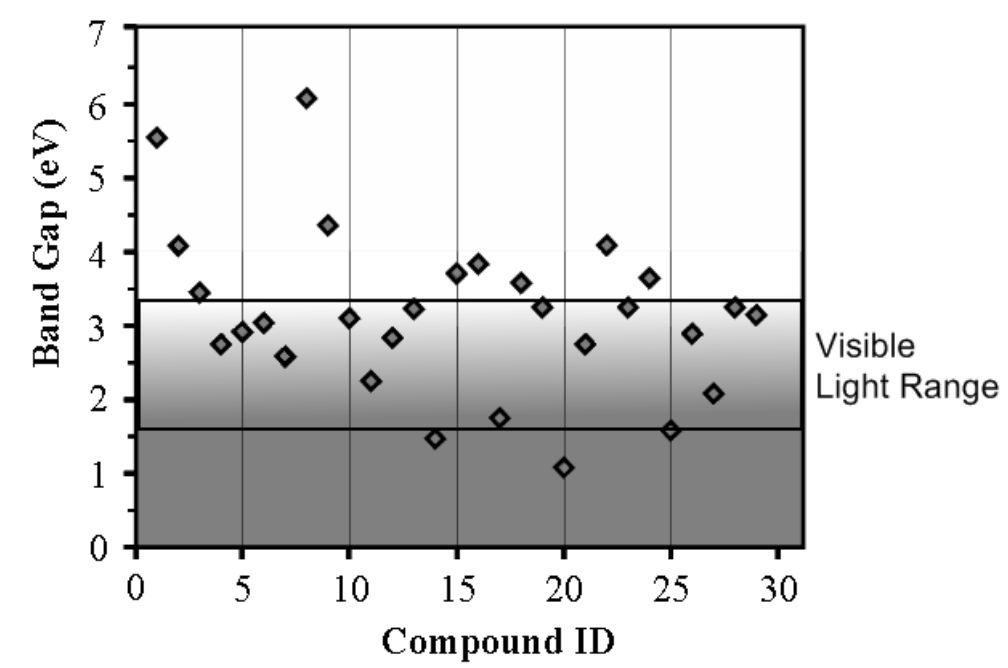

(ID 1-5) $\mathrm{MgH}_{2}, \mathrm{LiMgH}_{3}, \mathrm{NaMgH}_{3}, \mathrm{KMgH}_{3}, \mathrm{RbMgH}_{3}$; (ID 6-10) $\mathrm{CsMgH}_{3}, \mathrm{MgAlH}_{5}, \mathrm{MgB}_{2} \mathrm{H}_{8}$, $\mathrm{MgAl}_{2} \mathrm{H}_{8}, \mathrm{Ba}_{6} \mathrm{Mg}_{7} \mathrm{H}_{26}$; (ID 11-15) $\mathrm{BaMgH}_{4}, \mathrm{Ca}_{4} \mathrm{Mg}_{3} \mathrm{H}_{14}, \mathrm{Ca}_{19} \mathrm{Mg}_{8} \mathrm{H}_{54}, \mathrm{Ca}_{4} \mathrm{Mg}_{4} \mathrm{FeH}_{63}, \mathrm{CaMgNiH}_{4}$; (ID 16-20) $\mathrm{Cs}_{2} \mathrm{MgH}_{4}, \mathrm{Cs}_{3} \mathrm{MgH}_{5}, \mathrm{~K}_{2} \mathrm{MgH}_{4}, \mathrm{LiMg}_{2} \mathrm{RuH}_{6}, \mathrm{MgRuH}_{4}$; (ID 21-25) $\mathrm{Mg}_{3} \mathrm{ReH}_{7}, \mathrm{Rb}_{2} \mathrm{MgH}_{4}$, $\mathrm{Rb}_{3} \mathrm{MgH}_{5}, \mathrm{Rb}_{4} \mathrm{Mg}_{3} \mathrm{H}_{10}, \mathrm{SrMg}_{2} \mathrm{FeH}_{8}$; (ID 26-29) $\mathrm{SrMgH}_{4}, \mathrm{SrMgNiH}_{4}, \mathrm{Yb}_{4} \mathrm{Mg}_{3} \mathrm{H}_{14}, \mathrm{Sr}_{2} \mathrm{Mg}_{3} \mathrm{H}_{10}$. 
For instance, $\mathrm{MgH}_{2}$ is a colorless insulator with a band-gap of $E_{g}=5.16 \mathrm{eV}$. The optical band-gap of $\mathrm{Mg}-\mathrm{Ni}$ alloy $\left(\mathrm{Mg}_{2} \mathrm{NiH}_{4}\right)$, on the other hand, varies between 2.5 and $2.8 \mathrm{eV}$, depending on the presence of $\mathrm{Mg}$ rich areas which has been attributed to $\mathrm{MgH}_{2}$ segregation. Since the band-gap energy of these materials seems to be an important and determining factor, an overview of the band gaps is shown in Figure 9 and was prepared by Karazhanov et al. [22].According to the band-gap $\left(E_{\mathrm{g}}\right)$ theory, all incident light is transmitted when $E_{\mathrm{g}}$ of the material is greater than the energy of the visible light which ranges from $390 \mathrm{~nm}$ violet $(3.2 \mathrm{eV})$ to $760 \mathrm{~nm}$ red $(1.6 \mathrm{eV})$. When $E_{\mathrm{g}}$ value is in the range of the energy of the visible light $\left(1.6<E_{\mathrm{g}}<3.2 \mathrm{eV}\right)$, color change is expected, depending on the absorbed and emitted light wavelengths (gradient region). Finally, when $E_{\mathrm{g}}$ is less than the energy of the visible light, all the white light energy is absorbed and emitted, which results in a zero transparency (dark region). Figure 9 illustrates the basic idea about the expected optical response bands for magnesium containing metal-hydride compounds.

\section{Magnesium-Based Binary Alloys}

The importance of light-weight materials in hydrogen storage technology is obvious. Magnesiumbased alloys offer this potential. Therefore, lots of effort has been put into this research over a long period of time. For example, the extremely poor (de)hydrogenation kinetics of pure $\mathrm{Mg}$ have been significantly improved by the discovery of nano-structured alloying materials. In particular, ball-milling was successfully adopted by several research groups to produce interesting storage materials.

It has been shown that alloying $\mathrm{Mg}$ with transition metals has also a significant impact on the thermodynamics and kinetics of the hydride-formation reaction. $\mathrm{Mg}_{2} \mathrm{Ni}$ was the first alloy that was extensively studied in this respect [23-25]. Even though, this alloy has a better performance in terms of thermodynamics and kinetics, the hydrogen content in $\mathrm{Mg}_{2} \mathrm{NiH}_{4}$ is only about $3.6 \mathrm{wt} . \%$, which is less than half of that of pure $\mathrm{MgH}_{2}$.

Figure 10. Rutile $\mathrm{MgH}_{2}$ (a) and fluorite $\mathrm{Mg}_{\mathrm{x}} \mathrm{TM}_{(1-\mathrm{x})} \mathrm{H}_{2}$ (b).

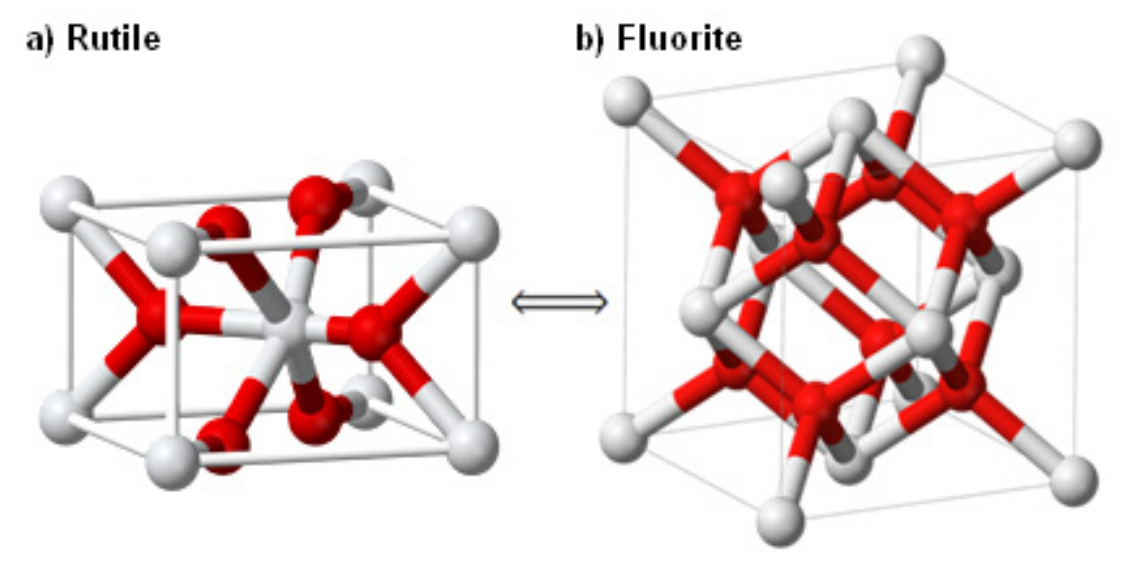

Under standard conditions, magnesium-dihydride has the rutile structure (see $\mathrm{MgH}_{2}$ Figure 10 a) with space group P42/mnm (136). Magnesium and hydrogen atoms are located in $2 a$ and $4 f$ Wyckoff positions, respectively. Each magnesium atom is coordinated octahedrally by hydrogen atoms. Mainly, 
the hydrides of the transition metals in the $4^{\text {th }}$ and $5^{\text {th }}$ row of the $3 \mathrm{~B}$ to $6 \mathrm{~B}$ groups crystallize in a fluorite structure $\left(\mathrm{MgTMH}_{2}\right.$ see Figure $\left.10 \mathrm{~b}\right)$ with space group Fm3m (225) and transition metal atoms in $4 a$ and hydrogen atoms in $8 c$ Wyckoff positions [26]. Alloying these transition metals helps to preserve the fluorite structure in $\mathrm{Mg}_{\mathrm{x}} \mathrm{TM}_{(1-\mathrm{x})} \mathrm{H}_{2}$ while $\mathrm{MgH}_{2}$ has the rutile structure which is denser. Consequently, the hydrogen mobility is limited whereas $\operatorname{Mg}_{\mathrm{x}} \mathrm{TM}_{(1-\mathrm{x})} \mathrm{H}_{2}(\mathrm{x}<0.8)$ adopts the fluorite structure, which is more open for hydrogen transportation.

The hydrogen storage capacity of these fluorite-structured compounds was shown to have a much larger reversible electrochemical storage capacity with respect to Mischmetal-based $\mathrm{AB}_{5}$ compounds in both thin film and bulk form. Comparing the extracted amount of charge of a fully hydrogenated $\mathrm{AB}_{5}$-type hydride-forming electrode (curve (a) in Figure 11) with that of a fluorite-stabilized magnesium-based compound (curve (b) in Figure 11) reveals that the latter has about four times higher storage capacity. In addition, the rates at which hydrogen can be electrochemically loaded and removed in fluorite-structured Mg-alloys were substantial, making these fluorite-stabilized materials very interesting.

Figure 11. Comparison between (a) $\mathrm{AB}_{5}$ type compound and (b) $\mathrm{Mg}_{0.72} \mathrm{Sc}_{0.28}\left(\mathrm{Pd}_{0.012} \mathrm{Rh}_{0.012}\right)$.

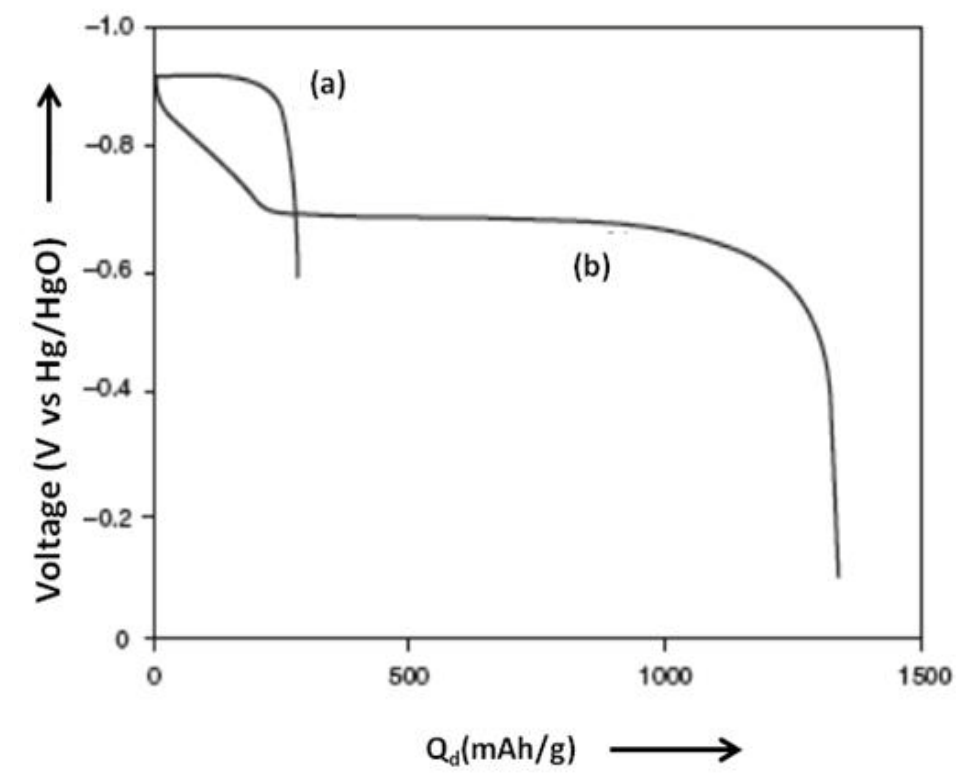

\subsection{Magnesium Scandium Alloys}

The specific fluorite-type of magnesium-based compounds alloyed with scandium has been studied electrochemically with compositions ranging from 50 to 100 at.\%, both in thin film and bulk forms. The thin film electrodes were prepared with a thickness of $200 \mathrm{~nm}$ on quartz substrates capped with a $10 \mathrm{~nm}$ Pd layer whereas the bulk powders were prepared through arc melting in a molybdenum crucible $\mathrm{Mg}_{\mathrm{x}} \mathrm{Sc}_{1-\mathrm{x}} \mathrm{Pd}_{0.24}$. The XRD results of the thin films confirm the formation of HCP solid solution irrespective of the composition. This is far from the equilibrium state reported in the phase diagram, where a Cs-Cl type solid solution is found between $\mathrm{x}=50-65$ at. $\% \mathrm{Mg}$ and single phase $\alpha-\mathrm{Mg}$ is only formed beyond 80 at.\% of Mg. The XRD results of bulk powders, on the other hand, confirm the equilibrium phase diagram. 
However, the electrochemical properties of $\mathrm{Mg}-\mathrm{Sc}$ thin films and bulk materials are very similar. Both thin film and bulk materials show similar trends in storage capacity and the shape of the discharge curves are also very similar for the various compositions (Figure 12). The maximum storage capacity was reached at a composition of 80 at.\% $\mathrm{Mg}$ and was $1740 \mathrm{mAh} / \mathrm{g}$ for thin films, corresponding to $6.5 \mathrm{wt} . \%$ of Hydrogen and $1495 \mathrm{mAh} / \mathrm{g}(5.6 \mathrm{wt} \%$ ) for bulk materials. The rate capability of the thin films is, however, much better than that of the bulk materials due to shorter diffusion lengths. [27,28].

Figure 12. Galvanostatic discharge curves of: thin films (a) and bulk materials (b); the current density was $1000 \mathrm{~mA} / \mathrm{g}$ for the thin films and $50 \mathrm{~mA} / \mathrm{g}$ for the bulk materials [28].

(a)
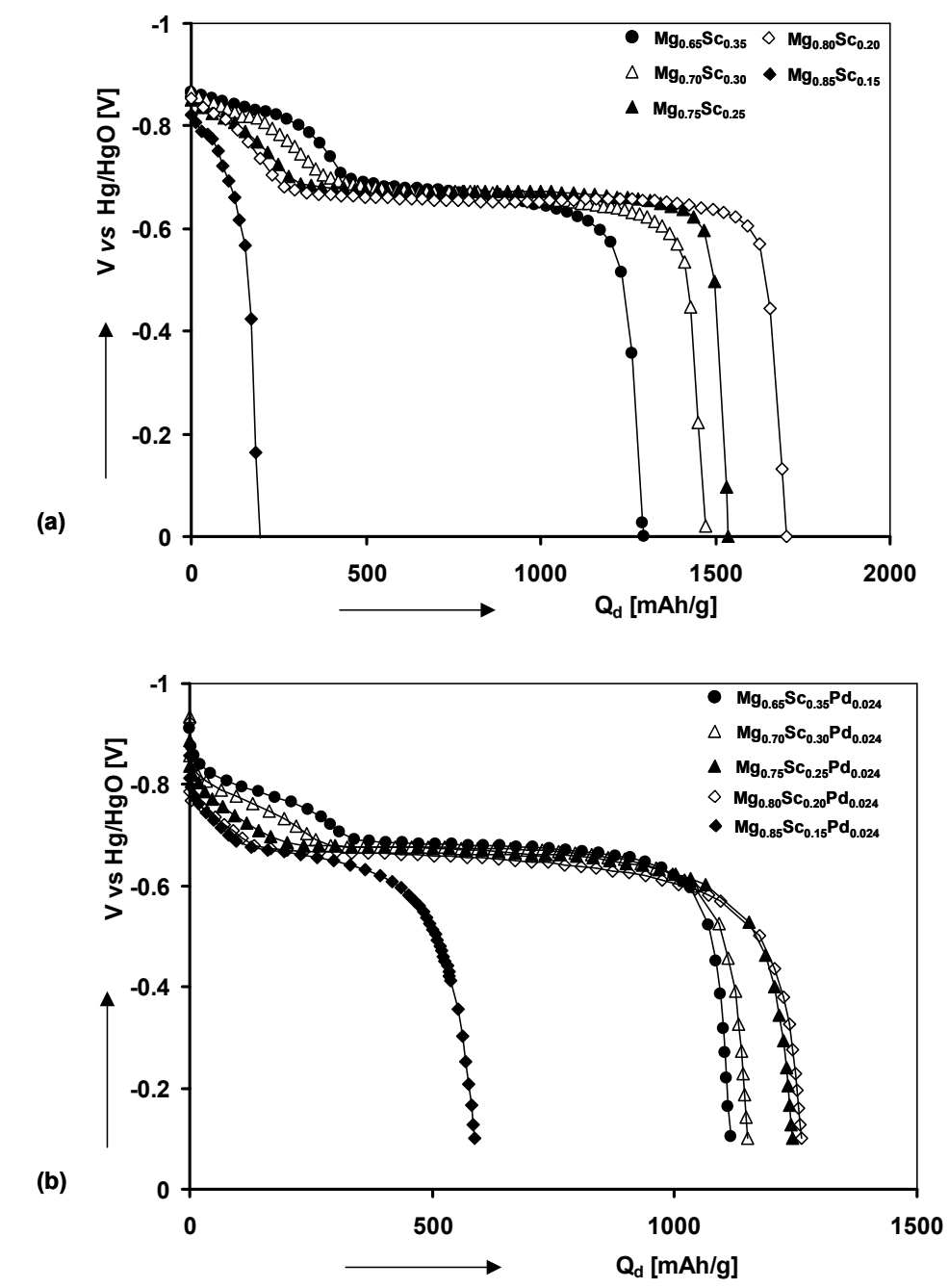

It was found that the favorable discharge kinetics was retained up to 80 at.\% magnesium. The improvement of the (de)hydriding kinetics compared to pure magnesium has been attributed to the more open fluorite structure of scandium-hydride instead of the more compact rutile structure of the conventional magnesium-hydrides. The plateau pressure is not a function of composition and almost equal to the equilibrium pressure of pure $\mathrm{MgH}_{2}$. Diffraction data obtained from the bulk system elucidates that the fully charged hydride is a single-phase fcc-structured hydride and no phase segregation into $\mathrm{MgH}_{2}$ and $\mathrm{ScH}_{2}$ has taken place [28]. 
Recently, the crystal structure of a palladium-containing $\mathrm{Mg}_{65} \mathrm{Sc}_{35}$ compound has been studied upon hydrogenation by neutron diffraction [29]. The metallic phase adopts a pseudo-CsCl-type structure. When hydrogenated, the structure changes from pseudo- $\mathrm{CsCl}$ to fcc involving an elongation along the c-axis and shrinkage along the a-axis (Figure 13). Upon deuteration, a two-phase domain is subsequently observed between 0.85 and $1.55[\mathrm{D} / \mathrm{M}]$ with two hydrides in equilibrium. Above this value, a pressure increase becomes apparent in the isotherm, leading to fully occupied tetrahedral sites and partially filled octahedral sites [30].

Figure 13. Neutron diffraction of $\mathrm{Mg}_{0.65} \mathrm{Sc}_{0.35}$ (a) before deuterium loading (b) after deuterium loading [30].

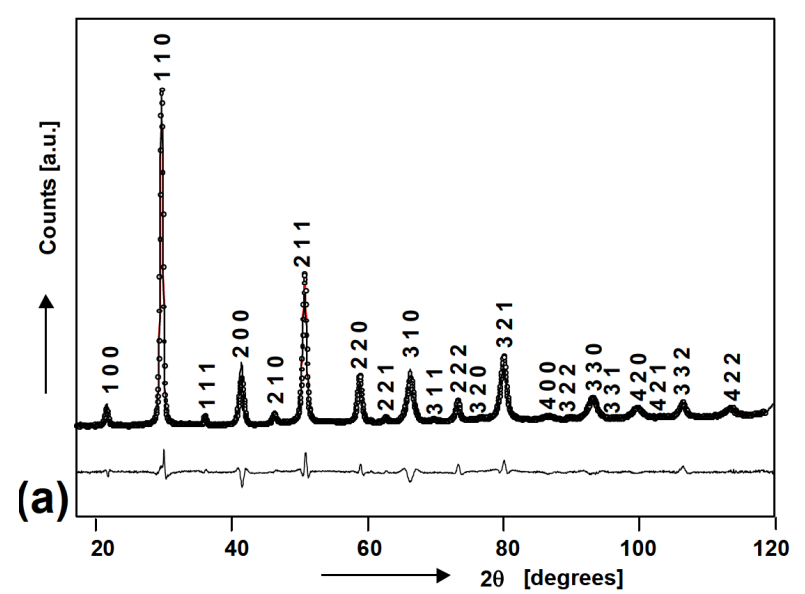

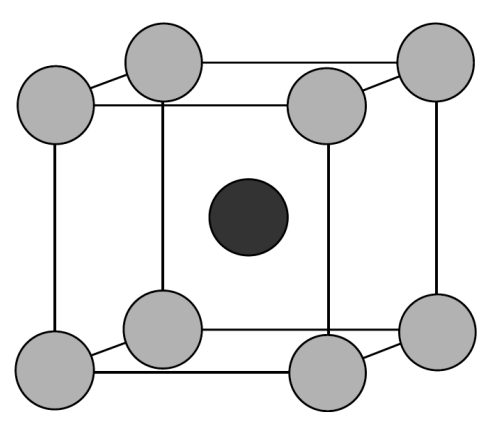

$a=3.592 \AA$
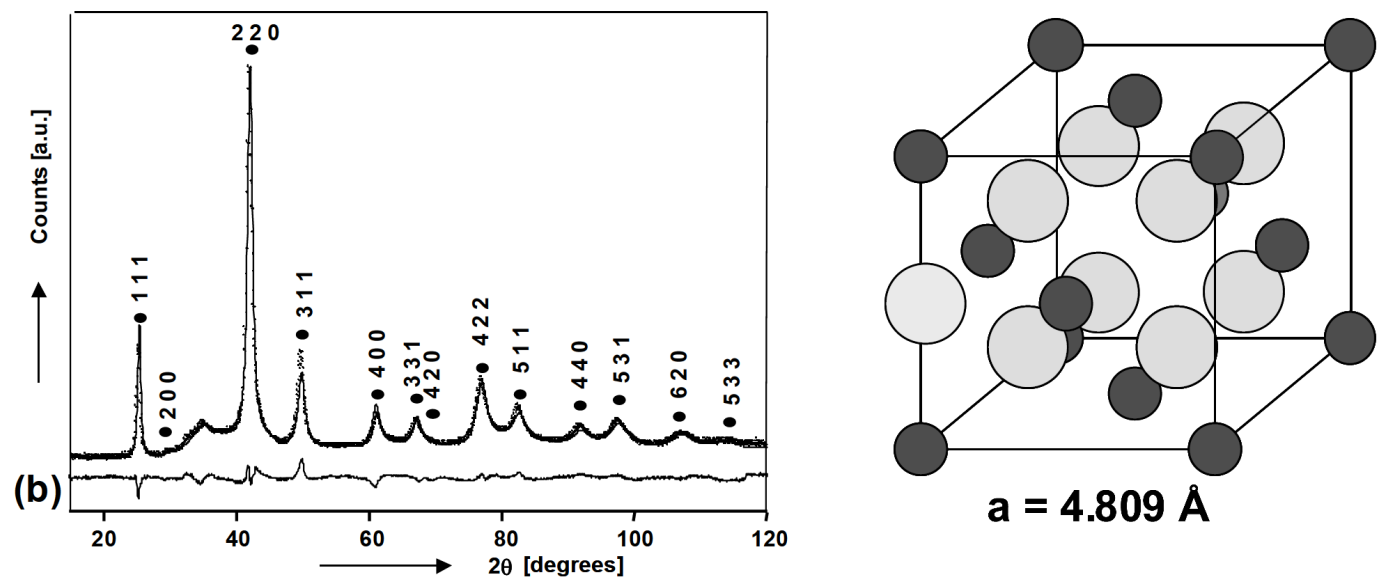

It has been argued that interstitial hydrogen is highly mobile, due to the large and partially occupied octahedral sites that that favorably influence the transportation properties. Using proton nuclear magnetic resonance (NMR), the crystallography has been proven to be responsible for the beneficial transportation properties of the fluorite-structured magnesium compounds. The frequency hopping rate for the fluorite-structured compounds at the relevant temperatures was found to be many orders of magnitude higher than that for the rutile-structured material. At any given temperature, the hopping rate of $\mathrm{Mg}_{(1-\mathrm{y})} \mathrm{Sc}_{\mathrm{y}} \mathrm{H}_{\mathrm{x}}$ is faster than in $\mathrm{ScH}_{2}$ and much faster than in the ionic $\mathrm{MgH}_{2}$, but still slower than in $\mathrm{LaNi}_{5} \mathrm{H}_{6.8}$ (Figure 14) [31].

First principle calculations were done on $\mathrm{Mg}_{(1-\mathrm{y})} \mathrm{Sc}_{\mathrm{y}}$ alloys by Pauw et al. [32]. Figure 15 shows that the decrease in the formation enthalpy with increasing Sc-content is more pronounced for the fluorite 
structure than for the rutile structure. The crossing point of the two curves is located around $20 \% \mathrm{Sc}$ $(y=0.20$ in Figure 16), which is the exact composition where the electrochemical results showed the maximum rate capability and hence electrochemical storage capacity. The first principle calculations are in good agreement with these experimental findings.

Figure 14. Relaxation map showing rate $\omega_{\mathrm{H}}$ of $\mathrm{H}$ hopping as a function of reciprocal temperature in $\mathrm{MgH}_{2}, \mathrm{ScH}_{2}, \mathrm{Mg}_{(1-y)} \mathrm{Sc}_{\mathrm{y}} \mathrm{H}_{\mathrm{x}}$, and $\mathrm{LaNi}_{5} \mathrm{H}_{6.8}$ [31].

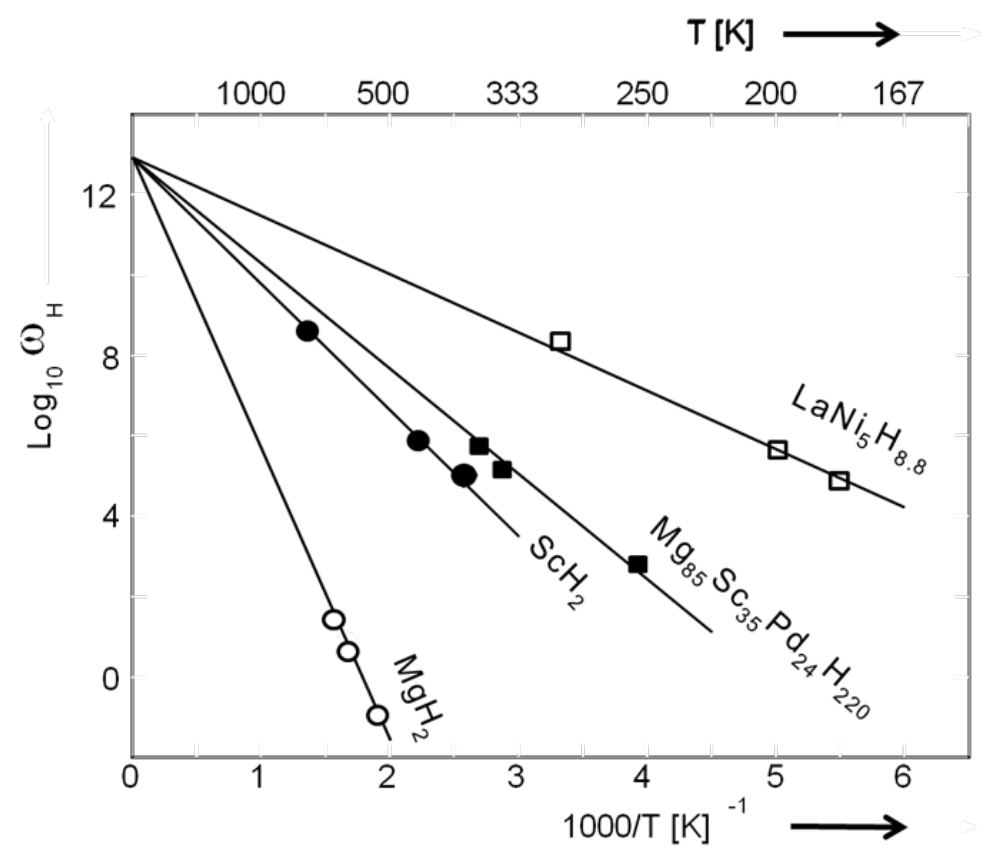

Figure 15. Enthalpies of formation of $\mathrm{Mg}_{1-\mathrm{y}} \mathrm{Sc}_{\mathrm{y}} \mathrm{H}_{2}$. (a) Rutile (b) fluorite [32].

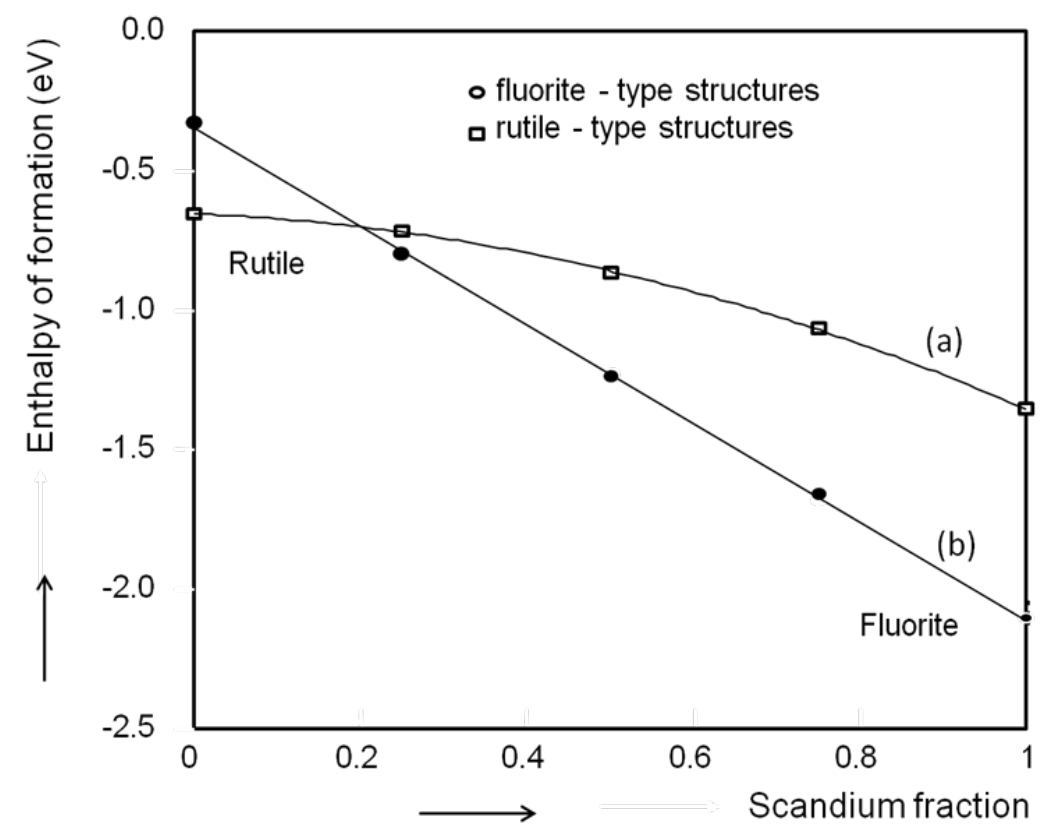




\subsection{Magnesium Titanium Alloys}

Since scandium is rather expensive, attempts to find cheaper substitutes were recently undertaken. Titanium dihydrides are also promising candidates because of having the same fluorite structure as that of scandium dihydride. Experiments performed with $\mathrm{Mg}_{0.80} \mathrm{Ti}_{0.20}$ thin film electrodes indeed showed a similar drastic improvement of the discharge (dehydrogenation) kinetics compared to pure magnesium hydride $\left(\mathrm{MgH}_{2}\right)$. A more elaborate study on the $\mathrm{Mg}$-Ti system (Figure 16) revealed that the composition dependence of the hydrogen storage capacity was quite similar to that of the $\mathrm{Mg}-\mathrm{Sc}$ system, also showing a maximum capacity around 80 at.\% magnesium [33].

Figure 16. Electrochemical determined reversible electrochemical capacity at room temperature as a function of magnesium content in $\mathrm{Mg}$-Ti thin film electrodes.

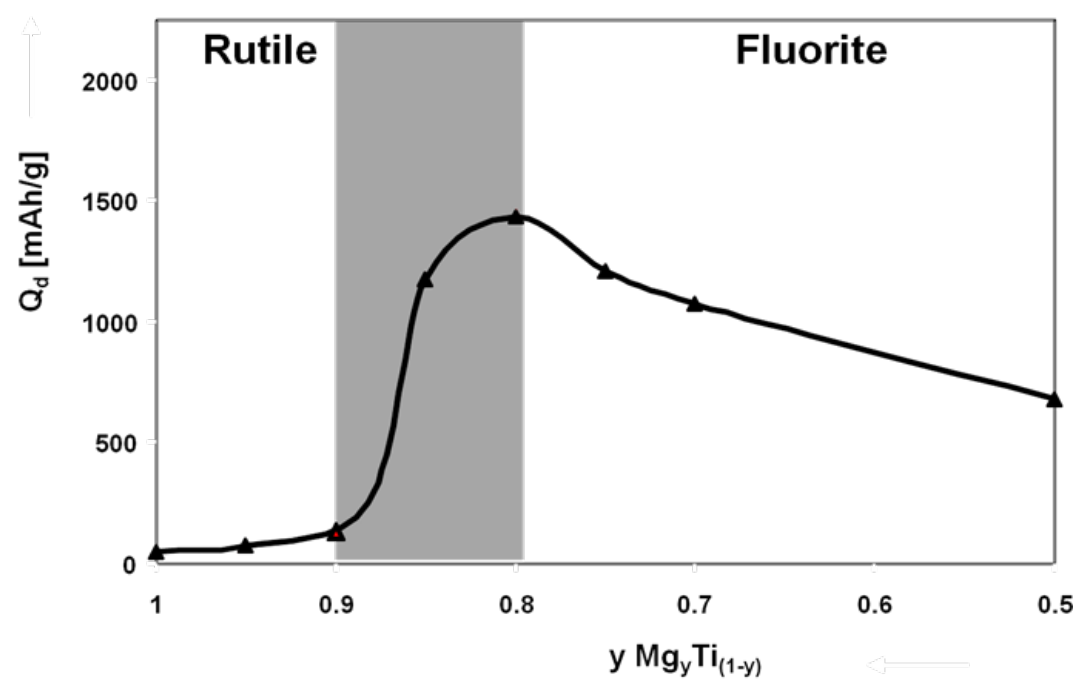

Pauw et al. [32] also investigated the formation enthalpies of metal hydrides in both the rutile and fluorite structure. The calculations showed that the addition of $\mathrm{Ti}$ induces a remarkable change in the crystal structure compared to pure $\mathrm{MgH}_{2}$. The formation enthalpy of rutile $\mathrm{Mg}_{0.50} \mathrm{Ti}_{0.50} \mathrm{H}_{2}$ is $-0.421 \mathrm{eV} / \mathrm{H}_{2}$, which is $22.7 \mathrm{~kJ} \mathrm{~mol}^{-1}$ less negative than that of pure $\mathrm{MgH}_{2}$. The rutile structure with composition $\mathrm{Mg}_{0.25} \mathrm{Ti}_{0.75} \mathrm{H}_{2}$ is also less stable than $\mathrm{MgH}_{2}$, which means that Ti destabilizes the rutile structure over almost the entire compositional range. The formation enthalpy of the fluorite structure shows a tendency towards more negative values over the entire compositional range, the same as for the Mg-Sc system. The fluorite structure becomes the most stable phase around $\mathrm{y}=0.20$, which is also very similar to $\mathrm{Mg}$-Sc and these theoretical results are therefore in good agreement with the experimental results. The crystal structure of the resulting hydrides seems to play a crucial role in determining the (de)hydrogenation kinetics for this interesting new class of hydrogen storage materials [32].

In situ electrochemical XRD was carried out by Vermeulen et al. to investigate the crystallographic phase transformation during the electrochemical hydrogenation of the MgTi alloys [34]. While hydrogenating $\mathrm{Mg}_{0.90} \mathrm{Ti}_{0.10}$ thin films electrochemically, the hexagonal reflections decrease with increasing hydrogen content (Figure 17 a). Simultaneously, the bct reflections evolve, indicating the formation of a body centered tetragonal phase which is the same as for pure $\mathrm{MgH}_{2}$. On the other hand, hydrogenation of $\mathrm{Mg}_{0.70} \mathrm{Ti}_{0.30}$ showed an increase in the fcc phase (Figure $17 \mathrm{~b}$ ). Substantial electrochemical storage capacities of more than $1500 \mathrm{mAh} \mathrm{g}^{-1}$ have been reported for the $\mathrm{Mg}-\mathrm{Ti}$ 
system at room temperature. This corresponds to a reversible hydrogen content of about $6 \mathrm{wt} . \%$. In addition, it has been shown that these meta-stable materials cannot only be produced by thin film evaporation and sputtering techniques but also by mechanical alloying.

Several attempts have been made by researchers to produce $\mathrm{Mg}$ - $\mathrm{Ti}$ alloys by mechanical alloying. Rousselot et al. investigated the phase transformation during electrochemical hydrogenation [35]. The meta-stable hcp $\mathrm{Mg}_{0.50} \mathrm{Ti}_{0.50}$ alloy was formed through mechanical alloying. XRD was performed on the electrochemically hydrogenated alloy. Upon cycling, the intensity of the hcp phase decreases and a new peak arises, which corresponds to hydrided fcc phase. The fcc phase is irreversibly formed and does not disappear after dehydrogenation, instead a slight decrease in the lattice constant was observed upon discharge. Kalisvaart et al. reported the formation of two fcc phases of the Mg-Ti alloy when the milling process was carried out with stearic acid as process control agent [36,37]. Among the two fcc phases only one was concluded to be electrochemically active. The storage capacity of this bulk material was reported to be $500 \mathrm{mAh} / \mathrm{g}$.

Figure 17. In-situ electrochemical XRD measurements of $\mathrm{Mg}_{0.90} \mathrm{Ti}_{0.10}(\mathbf{a})$ and $\mathrm{Mg}_{0.70} \mathrm{Ti}_{0.30}$ (b) during hydrogenation [34].

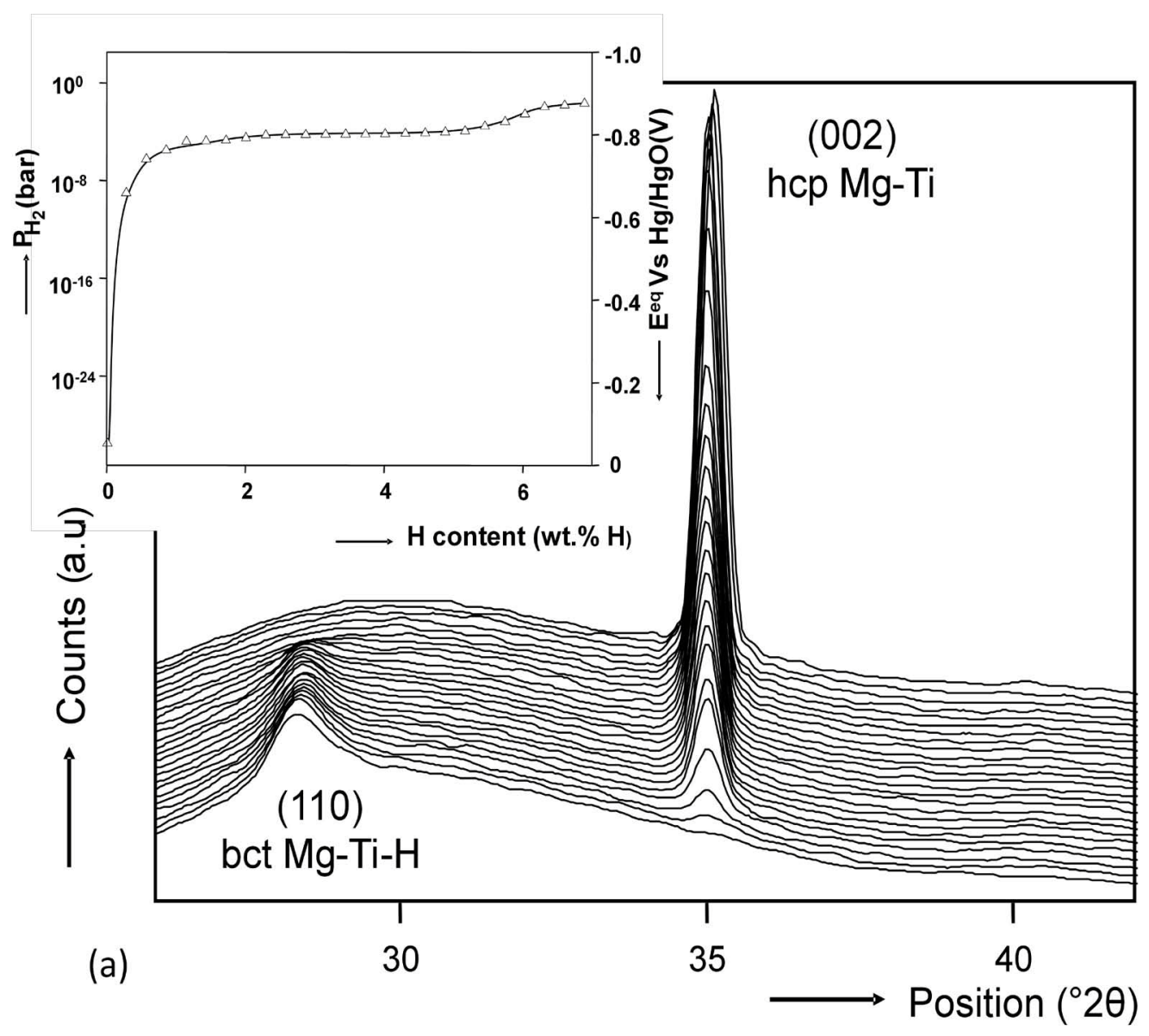


Figure 17. Cont.

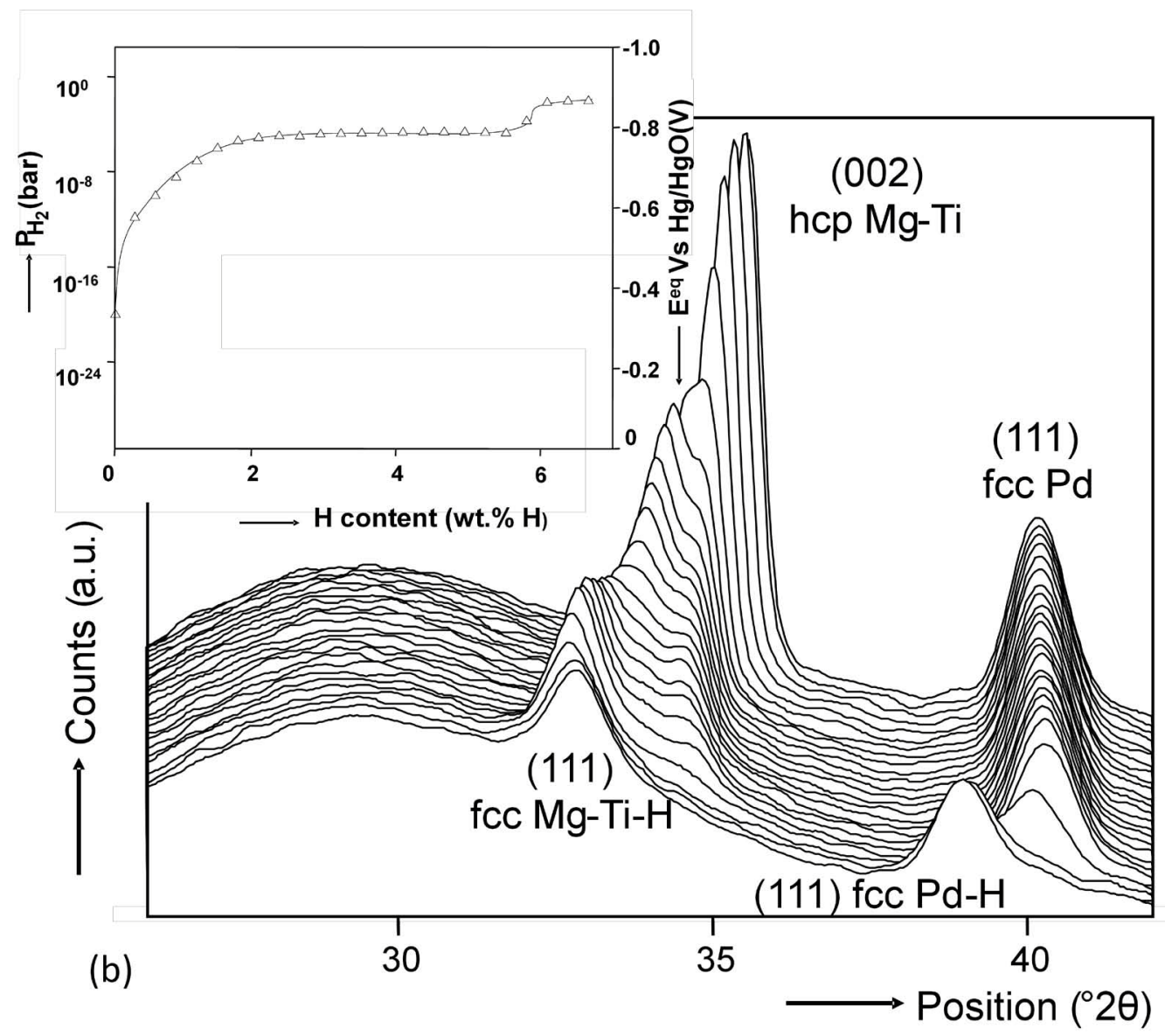

Kyoi et al. synthesized Mg-Ti-H compound at $600{ }^{\circ} \mathrm{C}$ in a high-pressure anvil cell above 8 GPa by mixing $\mathrm{MgH}_{2}$ and $\mathrm{TiH}_{1.9}$ [38]. The metal atom structure was found to be close to the $\mathrm{Ca}_{7} \mathrm{Ge}$ type fcc structure. This is in line with the findings of Vermeulen et al [34]. It could be concluded from in situ XRD studies that the hydrogen atoms occupy the tetrahedral sites.

The Mg-Ti alloy has a positive heat of mixing and must therefore be considered as an immiscible system [39]. The alloy can therefore, in principle, not be synthesized under equilibrium conditions and thus the only way to produce these meta-stable materials is by making use of non-equilibrium preparation methods. The stability of the meta-stable alloys is still questionable at high temperature and pressure conditions. Liang et al. reported an extended solubility of $\mathrm{Ti}$ in $\mathrm{Mg}$, during mechanical alloying of $\mathrm{Mg}$ and $\mathrm{Ti}$ [40]. In the case of $\mathrm{Mg}$ with 20 at.\% $\mathrm{Ti}$, about 12.5 at.\% $\mathrm{Ti}$ is dissolved in the $\mathrm{Mg}$ lattice when the mechanical alloying process reaches a stable state, while the rest remains as fine particles of size $50-150 \mathrm{~nm}$ in diameter. Dissolution of $\mathrm{Ti}$ in the $\mathrm{Mg}$ lattice causes a decrease in unit cell volume. The phase segregation begins at high temperature and the supersaturated $\mathrm{Mg}$-Ti alloys start to decompose at $200{ }^{\circ} \mathrm{C}$. Hydrogenation is an exothermic reaction and enhances the decomposition process.

Srinivasan et al. investigated the structure of bulk magnesium-titanium deuteride $\operatorname{Mg}_{0.65} \operatorname{Ti}_{0.35} \mathrm{D}_{x}$ prepared via mechanical alloying and deuterium gas-phase loading at 75 bars and $175{ }^{\circ} \mathrm{C}$ [41]. The structural analysis was made with XRD, NMR and neutron diffraction. Deuterium loading causes the formation of both interdispersed rutile $\mathrm{MgD}_{2}-\mathrm{TiD}_{y}$ nano-domains and a separate fluorite $\mathrm{TiD}_{z}$ phase. Exchange NMR technique indicates complete deuterium exchange between the $\mathrm{MgD}_{2}$ and $\mathrm{TiD}_{y}$ phase 
within one second. Gas phase hydrogenation of the Mg-Ti alloys at higher temperatures increases the risk of phase segregation.

Even though the kinetics of the fluorite-structured compounds is faster compared to the $\mathrm{MgH}_{2}$, the thermodynamic properties are not improved by the addition of these transition metals. For instance, the dehydrogenation enthalpy of $\mathrm{Mg}_{\mathrm{x}} \mathrm{Sc}_{(1-\mathrm{x})} \mathrm{H}_{2}$ and $\mathrm{Mg}_{\mathrm{x}} \mathrm{Ti}_{(1-\mathrm{x})} \mathrm{H}_{2}$ is higher compared to $\mathrm{MgH}_{2}$. Thus, high temperature is required to dehydrogenate these compounds in case of gas phase loading. However, only $\mathrm{Mg}-\mathrm{Sc}$ alloys are stable with respect to decomposition into its elemental metallic form. Since scandium is expensive, the next optional metal $\mathrm{Ti}$ is preferred considering the storage capacity compared to $\mathrm{Cr}$ and V. Due to the high stability of the Mg-Ti hydrides and low thermal stability of Mg-Ti alloy, the addition of a third element into the binary alloys is required to stabilize the host materials and, consequently, to destabilize the alloy hydrides. Careful selection of the third alloying element could assist in improving the thermodynamic properties while maintaining the storage capacities.

\subsection{Mg-Based Ternary Alloys}

Increasing the plateau pressure of the metal-hydrogen system can be accomplished by destabilization of the metal hydride. Miedema proposed a mathematical model to calculate the effect on the thermodynamic stability of an additional element(s) to the metallic compound $[42,43]$. The Miedema model was used by Vermeulen et al. to screen elements that stabilize the metallic Mg-Ti system [44]. Al and $\mathrm{Si}$ were selected to destabilize the $\mathrm{Mg}$-Ti alloy, due to their advantageous lightweight mass to maintain the high gravimetric capacity of the overall $\mathrm{Mg}$-Ti alloy. The isothermal curves of the $\mathrm{Mg}_{0.69} \mathrm{Ti}_{0.21} \mathrm{Al}_{0.10}$ alloy show two plateau regions, a plateau up to $4 \mathrm{wt} \%$ of Hydrogen at $10^{-6}$ bars and a second sloping plateau which lies at higher pressures (Figure 18).

Addition of higher $\mathrm{Al}$ content in the $\mathrm{Mg}$-Ti lattice leads to a decrease in the reversible storage capacity. If only 10 at.\% is incorporated in Mg-Ti alloy with a high Mg-content, it does not seem to significantly affect the reversible capacity. The declining capacity at high Al content could be due to kinetic limitations imposed by the material. Additionally, Si also clearly affects the isotherms compared to Mg-Ti alloys. The length of the first plateau decreases, when $P_{\mathrm{H}_{2}}$ increases steeply and soon reaches a sloping plateau. Since $\mathrm{Si}$ is heavier than Al, the storage capacity is lower than that of the Al-containing ternary alloys. The occurrence of the second plateau was also observed in other systems, such as $\mathrm{Mg}_{2} \mathrm{CuAl}_{0.375}, \mathrm{LaCo}_{6}, \mathrm{Ti}-\mathrm{Fe}$ and $\mathrm{NdCo}_{5}$. Interestingly, the $\mathrm{Mg}$-Ti-Al-H system shows a plateau near atmospheric pressure and temperature. 
Figure 18. Electrochemically determined dehydrogenation isotherms of $200 \mathrm{~nm}$; (i-a) $\mathrm{Mg}_{0.69} \mathrm{Ti}_{0.21} \mathrm{Al}_{0.10}$ and (i-b) $\mathrm{Mg}_{0.80} \mathrm{Ti}_{0.20}$ thin films with a $10 \mathrm{~nm}$ Pd top-coat (ii-a) $\mathrm{Mg}_{0.55} \mathrm{Ti}_{0.35} \mathrm{Si}_{0.10}$ and (ii-b) $\mathrm{Mg}_{0.69} \mathrm{Ti}_{0.21} \mathrm{Si}_{0.10}$ films capped with $10 \mathrm{~nm} \mathrm{Pd}$ [44].
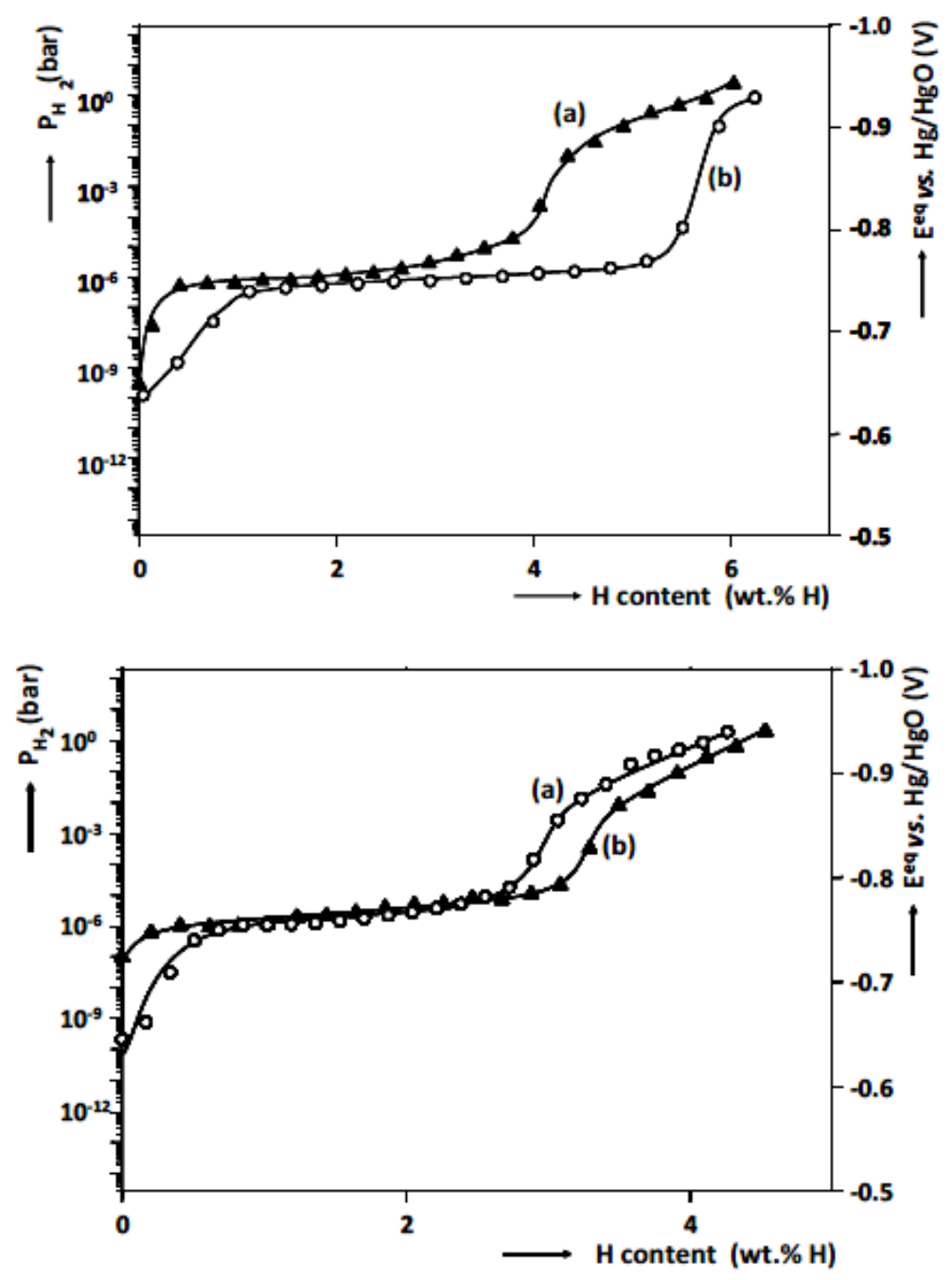

\section{Hydrogenography}

The introduction of hydrogenography by Griessen et al. in 2007 was an interesting approach to analyze gradient alloy compositions during the (de)hydrogenation cycles of alloy thin films [45]. This combinatorial method enables optically monitoring of the (de)hydrogenation of numerous compositions of alloying metals simultaneously under the same experimental conditions. Controlling the metal alloy composition is the key step in the hydrogenography technique. Off-centered, cosputterred two or more metals generate a series of heterogeneously deposited gradient compositions on the same substrate. Then, the different optical responses that are generated by multiple alloy compositions with respect to the hydrogen content are spatially analyzed via a CCD camera. Hydrogenography can be used as an in situ screening test to quickly find the optimal composition which performs faster optical conversion or higher transmission during hydrogen (un)loading. Depending on the research of interest, all optical responses (transparent, absorbent and reflecting states) with respect to the hydrogen content can be studied. 
For instance, by applying combinatorial hydrogenography, multi-compositional optical analyses can be performed in a single run by focusing on the spatially defined heterogeneous metal-hydride composition, as can be seen in Figure 19. In (a) and (b) binary $\operatorname{Mg}_{(1-y)} \operatorname{Ti}_{\mathrm{y}}$ alloys $(0.11 \leq \mathrm{y} \leq 0.4)$ and in (c) ternary gradient alloys with composition $\mathrm{Mg}_{\mathrm{y}} \mathrm{Ni}_{\mathrm{z}} \mathrm{Ti}_{(1-\mathrm{y}-\mathrm{z})}(0.4 \leq \mathrm{y} \leq 0.9$ and $0 \leq \mathrm{y} \leq 0.5)$ are analyzed by combined gas phase hydrogenation and in situ hydrogenography. The gradually varying optical responses upon hydrogenation can clearly be seen with respect to the different binary and ternary alloy compositions, indicating that the hydrogenation properties are strongly dependent on the materials composition [45].

Figure 19. Pressure-optical transmission isotherms of (a) continuously gradient $\mathrm{Mg}_{\mathrm{y}} \mathrm{Ti}_{(1-\mathrm{y})}$; (b) discrete compositions of $\mathrm{Mg}_{\mathrm{y}} \mathrm{Ti}_{(1-\mathrm{y})}$; and (c) phase image of ternary gradient $\mathrm{Mg}-\mathrm{Ni}-\mathrm{Ti}$ alloy hydrides. [45]
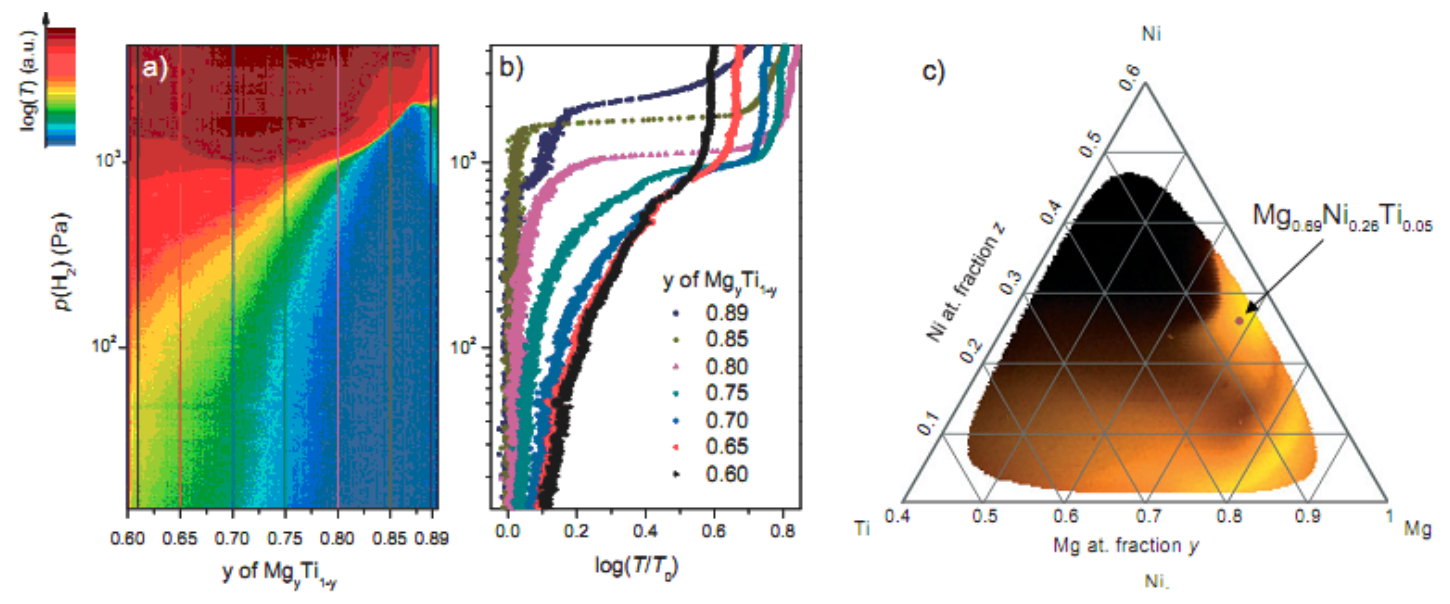

\section{Conclusions}

Metal-hydrides are promising candidates in terms of energy density, lightweight, safety and reversibility. Specifically, intensive work has been done upon magnesium-based alloy systems (up to $7.6 \mathrm{wt} \%$ of hydrogen storage capacity) to improve hydrogen storage properties. Electrochemical hydrogenation, which is widely analyzed in this work, does not only enable reversible, precise (dis)charging under ambient temperature and pressure but also combines fundamental studies of potential battery and fuel cell applications. Conceptually, stability modification of the metal/metal-hydride systems has been achieved by adding a second or even a third element to $\mathrm{Mg}$. Binary $\mathrm{Mg}_{\mathrm{x}} \mathrm{TM}_{(1-\mathrm{x})}(\mathrm{TM}$ $=\mathrm{Sc}$, Ti) possesses better kinetics compared to pure $\mathrm{MgH}_{2}$. However, these alloy-hydrides suffer from relatively poor thermal stability. Thus, the necessity of further alloying with foreign elements is emerging in order to adjust the thermal characteristics of the alloy-hydrides. Both Al and Si were found to be suitable ternary additives to binary alloys for achieving better thermodynamic properties.

On the other hand, magnesium-hydride potentially is an interesting candidate for switchable smart mirror applications due to its high band-gap energy of $E_{\mathrm{g}}=5.6 \mathrm{eV}$. The hydrides change from metal-to-semiconductor, which results in electrochromic and optical responses of the thin films as a function of the hydrogen content. Pioneering results showed that magnesium, alloyed with transition metals like gadolinium, titanium and nickel exhibits a conversion from the metallic reflective state to the semiconducting transparent state. 
Besides these promising results, these state-of-the-art materials are still far from meeting the goals for practical applications. Therefore, continued research work is needed to further improve the hydrogenation properties, such as reaction rate, thermal stability and cyclic behavior of the metal-hydrides.

\section{References}

1. Guo, Z.X.; Shang, C.; Aguey-Zinsou, K.F. Materials challenges for hydrogen storage. J. Eur. Ceram. Soc. 2008, 28, 1467-1473.

2. Momirlan, M.; Veziroglu, T.N. The properties of hydrogen as fuel tomorrow in sustainable energy system for a cleaner planet. Int. J. Hydrogen Energy 2005, 30, 795-802.

3. Züttel, A.; Borgschulte, A.; Schlapbach, L. Hydrogen as A Future Energy Carrier; Wiley-VCH Verlag GmbH \& Co. KGaA: Weinheim, Germany, 2008; p. 5.

4. Schlapbach, L.; Züttel, A. Hydrogen-storage materials for mobile applications. Nature 2001, 414, 353-358.

5. Ross, D.K. Hydrogen storage: The major technological barrier to the development of hydrogen fuel cell cars. Vacuum 2006, 80, 1084-1089.

6. Fukai, Y. The Metal-Hydrogen System, Basic Bulk Properties. In Springer Series in Materials Science; Springer: Berlin, Germany, 1993; pp. 55-88.

7. Van Vucht, J.H.N.; Kujipers, F.A.; Bruning, H.C.A.M. Reversible room-temperature absorption of large quantites of hydrogen by intermetallic compounds. Philips Res. Rep. 1970, 25, 133-140.

8. Selvam, P.; Viswanathan, B.; Swamy, C.S.; Srinivasan, V. Magnesium and magnesium alloy hydrides. Int. J. Hydrogen Energy 1986, 11, 169-192.

9. Luz, Z.; Genossar, J.; Rudman, P.S. Identification of the diffusing atom in $\mathrm{MgH}_{2}$. J. Less Common Metals 1980, 73, 113-118.

10. Züttel, A. Materials for hydrogen storage. Mater. Today 2003, 6, 24-33.

11. Willems, J.J.G. Metal Hydride Electrodes Stability of LaNis-Related Compounds; Philips Research Laboratories: Eindhoven, The Netherlands, 1984; Volume 39, pp. 1-94.

12. Notten, P.H.L. Rechargeable Nickel-Metal hydride Batteries: A Successful New Concept. In Interstitial Intermetallic Alloys; Grandjean, F., Long, G.L., Buschow, K.H.J., Eds.; Kluwer Academic Publishers: Dordrecht, The Netherlands, 1995; Volume 281, p. 151.

13. Platt, J.R. Electrochromism, a Possible Change of Color Producible in Dyes by an Electric Field. J. Chem. Phys. 1961, 34, 862-863.

14. Deb, S.K. A Novel electrophotographic system. Appl. Opt. 1969, 8, 192-195.

15. Huiberts, J.N.; Griessen, R.; Rector, J.H.; Wijngaarden, R.J.; Dekker, J.P.; de Groot, D.G.; Koeman, N.J. Yttrium and lanthanum hydride films with switchable optical properties. Nature 1996, 380, 231-234.

16. Griessen, R.; Giebels, I.A.M.E.; Dam, B. Optical Properties of Metal-Hydrides: Switchable Mirrors. Available online: http://www.nat.vu.nl/en/Images/ReviewSwitchableMirrors10AUG04_ tcm69-85550.pdf (accessed on 28 November 2011).

17. Notten, P.H.L.; Kremers, M.; Griessen, R. Optical switching of Y-hydride thin film electrodes. J. Electrochem. Soc. 1996, 143, 3348-3353. 
18. Van der Sluis, P.M.; Ouwerkerk, M.; Duine, P.A. Optical switching based on magnesium lanthanide alloy hydrides. Appl. Phys. Lett. 1997, 70, 3356-3358.

19. Griessen, R.; van der Sluis, P. Schaltbare Spiegel-Elektronenkorrelationen in der Anwendung. Physik Unserer Zeit 2001, 32, 76-83.

20. Niessen, R.A.H.; Notten, P.H.L. Electrochemical hydrogen storage characteristics of thin film $\mathrm{MgX}(\mathrm{X}=\mathrm{Sc}$, Ti, V, Cr) compounds. Electrochem. Solid State Lett. 2005, 8, A534-A538.

21. Richardson, T.J.; Slack, J.L.; Armitage, R.D.; Kostecki, R.; Farangis, B.; Rubin, M.D. Switchable mirrors based on nickel-magnesium films, Appl. Phys. Lett. 2001, 78, 3047-3049.

22. Karazhanov, S.Zh.; Ulyashin, A.G.; Vajeeston, P.; Ravindran, P. Hydrides as materials for semiconductor electronics. Philos. Mag. 2008, 88, 2461-2476.

23. Reilly, J.J.; Wiswall, R.H. Reaction of hydrogen with alloys of magnesium and nickel and the formation of $\mathrm{Mg}_{2} \mathrm{NiH}_{4}$. Inorg. Chem. 1968, 7, 2254-2256.

24. Janot, R.; Aymard, L.; Rougier, A.; Nazri, G.; Tarascon, J. Enhanced hydrogen sorption capacities and kinetics of $\mathrm{Mg}_{2} \mathrm{Ni}$ alloys by ball-milling with carbon and Pd coating. J. Mater. Res. 2003, 18, 1749-1752.

25. Zhang, S.G.; Hara, Y.; Suda, S.; Morikawa, T.; Inoue, H.; Iwakura, C. Physicochemical and electrochemical hydriding-dehydriding characteristics of amorphous $\operatorname{MgNi}_{\mathrm{x}}(\mathrm{x}=1.0,1.5,2.0)$ alloys prepared by mechanical alloying. J. Solid State Electrochem. 2001, 5, 23-28.

26. Süleyman, Er.; Tiwari, D.; de Wijs, G.A.; Brocks, G. Tunable Hydrogen Storage in MagnesiumTransition Metal Compounds: First-Principles Calculations. Phys. Rev. B 2009, 79, 1-8.

27. Niessen, R.A.H.; Notten, P.H.L. Hydrogen storage in thin film magnesium-scandium alloys. J Alloy Compd. 2005, 404-406, 457-460.

28. Kalisvaart, W.P.; Niessen, R.A.H.; Notten, P.H.L. Electrochemical hydrogen storage in MgSc alloys: A comparative study between thin films and bulk materials. J. Alloy Compd. 2006, 417, 280-291.

29. Latroche, M.; Kalisvaart, P.; Notten, P.H.L. Crystal structure of $\mathrm{Mg}_{0.65} \mathrm{Sc}_{0.35} \mathrm{D}_{\mathrm{x}}$ deuterides studied by X-ray and neutron powder diffraction. J. Solid State Chem. 2006, 179, 3024-3032.

30. Kalisvaart, W.P.; Latroche, M.; Cuevas, F.; Notten, P.H.L. In situ neutron diffraction study on Pd-doped $\mathrm{Mg}_{0.65} \mathrm{Sc}_{0.35}$ electrode material. J. Solid State Chem. 2008, 181, 1141-1148.

31. Conradi, M.S.; Mendenhall, M.P.; Ivancic, T.M.; Carl, E.A.; Browning, C.D.; Notten, P.H.L.; Kalisvaart, W.P.; Magusin, P.C.M.M.; Bowman, R.C., Jr.; Hwang, S.; Adolphi, N.L. NMR to determine rates of motion and structures in metal-hydrides. J. Alloy Compd. 2007, 446-447, 499-503.

32. Pauw, B.R.; Kalisvaart, W.P.; Tao, S.X.; Koper, M.T.M.; Jansen, A.P.J.; Notten, P.H.L. Cubic $\mathrm{MgH}_{2}$ stabilized by alloying with transition metals: A density functional theory study. Acta Mater. 2008, 56, 2948-2954.

33. Vermeulen, P.; Niessen, R.A.H.; Notten, P.H.L. Hydrogen storage in metastable $\mathrm{Mg}_{\mathrm{y}} \mathrm{Ti}_{(1-\mathrm{y})}$ thin films. Electrochem. Commun. 2006, 8, 27-32.

34. Vermeulen, P.; Wondergem, H.J.; Graat, P.C.J.; Borsa, D.M.; Schreuders, H.; Dam, B.; Griessen, R.; Notten, P.H.L. In situ electrochemical XRD study of (de)hydrogenation of $\mathrm{Mg}_{\mathrm{y}} \mathrm{Ti}_{(100-\mathrm{y})}$ thin films. J. Mater. Chem. 2008, 18, 3680-3687. 
35. Rousselot, S.; Bichat, M.P.; Guay, D.; Roué, L. Structure and electrochemical behaviour of metastable $\mathrm{Mg}_{50} \mathrm{Ti}_{50}$ alloy prepared by ball milling. J. Power Sources 2008, 175, 621-624.

36. Kalisvaart, W.P.; Notten, P.H.L. Mechanical alloying and electrochemical hydrogen storage of Mg-based systems. J. Mater. Res. 2008, 23, 2179-2187.

37. Kalisvaart, W.P.; Wondergem, H.J.; Bakker, F.; Notten, P.H.L. Mg-Ti based materials for electrochemical hydrogen storage. J. Mater. Res. 2007, 22, 1640-1649.

38. Kyoi, D.; Sato, T.; Rönnebro, E.; Kitamura, N.; Ueda, A.; Ito, M.; Katsuyama, S.; Hara, S.; Noréus, D.; Sakai, T. A new ternary magnesium-titanium hydride $\mathrm{Mg}_{7} \mathrm{TiH}_{\mathrm{x}}$ with hydrogen desorption properties better than both binary magnesium and titanium hydrides. J. Alloy Compd. 2004, 372, 213-217.

39. De Boer, F.R.; Boom, R.; Mattens, W.C.M.; Miedema, A.R.; Niessen, A.K. Cohesion in Metals; North-Holland: Amsterdam, The Netherlands, 1988; p. 127.

40. Liang, G.; Schulz, R. Synthesis of Mg-Ti alloy by mechanical alloying. J. Mater. Sci. 2003, 38, 1179-1184.

41. Srinivasan, S.; Magusin, P.C.M.M.; Kalisvaart, W.P.; Notten, P.H.L.; Cuevas, F.; Latroche, M.; van Santen, R.A. Nanostructures of $\mathrm{Mg}_{0.65} \mathrm{Ti}_{0.35} \mathrm{D}_{\mathrm{x}}$ studied with $\mathrm{x}$-ray diffraction, neutron diffraction, and magic-angle-spinning ${ }^{2} \mathrm{H}$ NMR spectroscopy. Phys. Rev. B 2010, 81, doi: 10.1103/PhysRevB.81.054107.

42. Miedema, A.R.; de Châtel, P.F.; de Boer, F.R. Cohesion in Alloys-fundamentals of a Semiempirical model. Physica B 1980, 100, 1-28.

43. Miedema, A.R. The electronegativity parameter for transition metals: Heat of formation and charge transfer of alloys. J. Less Common Metals 1973, 32, 117-136.

44. Vermeulen, P.; van Thiel, E.F.M.J.; Notten, P.H.L. Ternary MgTiX-alloys: A promising route towards low-temperature, high-capacity, hydrogen-storage materials. Chem. Eur. J. 2007, 13, 9892-9898.

45. Gremaud, R.; Broedersz, C.P.; Borsa, D.M.; Borgschulte, A.; Mauron, P.; Schreuders, H.; Rector, J.H.; Dam, B.; Griessen, R. Hydrogenography: An optical combinatorial method to find new light-weight hydrogen-storage materials. Adv. Mater. 2007, 19, 2813-2817.

(C) 2012 by the authors; licensee MDPI, Basel, Switzerland. This article is an open access article distributed under the terms and conditions of the Creative Commons Attribution license (http://creativecommons.org/licenses/by/3.0/). 